\title{
Numerical investigation of soot formation and oxidation processes under large two- stroke marine diesel engine-like conditions using integrated CFD-chemical kinetics
}

Pang, Kar Mun; Karvounis, Nikolas; Walther, Jens Honore; Schramm, Jesper

Published in:

Applied Energy

Link to article, DOI:

10.1016/j.apenergy.2016.02.081

Publication date:

2016

Document Version

Peer reviewed version

Link back to DTU Orbit

Citation (APA):

Pang, K. M., Karvounis, N., Walther, J. H., \& Schramm, J. (2016). Numerical investigation of soot formation and oxidation processes under large two-stroke marine diesel engine-like conditions using integrated CFD-chemical kinetics. Applied Energy, 169, 874-887. https://doi.org/10.1016/j.apenergy.2016.02.081

\section{General rights}

Copyright and moral rights for the publications made accessible in the public portal are retained by the authors and/or other copyright owners and it is a condition of accessing publications that users recognise and abide by the legal requirements associated with these rights.

- Users may download and print one copy of any publication from the public portal for the purpose of private study or research.

- You may not further distribute the material or use it for any profit-making activity or commercial gain

- You may freely distribute the URL identifying the publication in the public portal 
1 Numerical investigation of soot formation and oxidation processes under large two-stroke 2 marine diesel engine-like conditions using integrated CFD-chemical kinetics

4 Kar Mun Pang $^{*}, a, b$, Nikolas Karvounis ${ }^{b}$, Jens Honore Walther $^{b, c}$, Jesper Schramm $^{a}$

5

$6 \quad{ }^{a}$ Section of Thermal Energy, Department of Mechanical Engineering, Technical University of

7 Denmark, Nils Koppels Allé, 2800 Kgs. Lyngby, Denmark

$8 \quad{ }^{b}$ Section of Fluid Mechanics, Coastal and Maritime Engineering, Department of Mechanical

9 Engineering, Technical University of Denmark, Nils Koppels Allé, 2800 Kgs. Lyngby, Denmark

$10{ }^{c}$ Chair of Computational Science, ETH Zürich, Clausiusstrasse 33 ETH-Zentrum, CLT F 11, CH-

118092 Zürich, Switzerland

$13 *$ Corresponding author

14 Email: kmpan@mek.dtu.dk

16 Abstract

17 In this reported work, multi-dimensional computational fluid dynamics studies of diesel combustion and soot formation processes in a constant volume combustion chamber and a marine diesel engine are carried out. The key interest here is firstly to validate the coupling of a newly developed skeletal n-heptane mechanism and a revised multi-step soot model using laser extinction measurements of

21 diesel soot obtained at different ambient pressure levels in an optical accessible, constant volume 22 chamber experiment. It is revealed that ignition delay times and liftoff lengths generated using the 23 new skeletal model are close to those produced by the larger and more comprehensive chemical 24 mechanisms, apart from those at the low pressure condition. The current study also demonstrates that 
25 the variation of averaged soot volume fraction with respect to the change of combustion chamber

26 pressure captured using the revised soot model agrees reasonably well with the measurements in 27 terms of peak values. The numerical model is subsequently applied to investigate the flame 28 development, soot/nitrogen monoxide formation and heat transfer in a two-stroke, low-speed 29 uniflow-scavenged marine diesel engine operating at full load condition, where optical 30 measurements are not available. Comparisons to the experimental data show that the simulated 31 pressure rise starts 1.0 crank angle degree in advance and the calculated peak pressure is $1.7 \%$ lower. The associated flame liftoff length is negligible, yielding higher local equivalence ratio and soot volume fraction values as compared to those under similar test condition in the constant volume chamber. With the use of the revised model, the total heat transfer to the walls calculated when soot radiative heat loss is taken into account is approximately $30 \%$ higher compared to that when only convective heat loss is considered. The averaged nitrogen monoxide concentration is $7.7 \%$ lower when both convective and soot radiative heat losses are accounted for but the net soot mass production is less sensitive to soot radiation. A sensitivity study reveals that neither increasing nor decreasing the soot absorption coefficient by $30 \%$ from the baseline setup is influential to nitrogen monoxide formation, soot mass production and heat transfer. The findings here aid to gain insights and provide a better understanding of the combustion and soot processes in large, uniflow-scavenged marine engines. The numerical model developed in this work can also be applied to explore different phenomena in this combustion system.

Keywords: combustion, soot formation, diesel spray, two-stroke, marine engine 


\section{Introduction}

50 Large two-stroke, marine diesel engines dominate as prime movers for cargo ships due to their high

51 efficiency and reliability. In 2016, the International Maritime Organisation has enforced new

52 regulations for marine engines, with the aim to reduce emitted pollutants for instance, to reduce the

53 nitric oxides $\left(\mathrm{NO}_{\mathrm{x}}\right)$ by $80 \%$. Various experimental and numerical works have been carried out to aid

54 in complying with the increasingly stringent regulations [1,2]. Producing engines for low emission

55 limits without lowering the fuel efficiency is a challenging task. Indeed, both fuel efficiency and

56 formation of emissions are strongly dependent on the combustion characteristics, which is a result of

57 fuel spray development such as droplet breakup, evaporation and mixing with air. Meanwhile, the in-

58 cylinder flow plays a significant role in influencing the aforementioned processes. For an effective

59 control strategy of emissions formation, a detailed understanding of these processes is particularly

60 important. This can be achieved through the measurements from optical diagnostics such as $\mathrm{OH}^{*}$

61 chemiluminescence, laser induced incandescence, laser extinction and two-colour imaging method in

62 high-pressure combustion environment [3-9]. These optical diagnostics experiments were initially

63 carried out in constant volume combustion chambers [3-6] and small bore, high-speed engines [7-9].

64 Over the last decade, optical diagnostics research has been extended to medium- and low-speed

65 marine engines as well as constant volume chambers under conditions relevant for marine engines.

66 These experiments provide in-situ information regarding the in-cylinder velocity [10], fuel jet

67 development [11,12] and flame development [11]. Nevertheless, comprehensive experimental

68 investigations to elucidate the in-cylinder events are costly and time consuming owing to the

69 complex nature of the combustion and emissions formation processes. Implementation of optical

70 diagnostics under marine diesel engine relevant conditions is even more challenging due to the much

71 higher level of deposits from combustion and lubrication on optical lenses. Also, the optical view is 
small relative to the cylinder size of large marine diesel engines, limiting a complete monitoring of

73 the in-cylinder events. To date, reliable quantitative measurements under such conditions are limited.

As an alternative, numerical tools have been used to offer the opportunity to expand on the

75 limited details of experimental measurements through a more cost-effective manner. Zero-

76 dimensional multi-zone models are one of the efficient tools to achieve this purpose [13-15]. Multi-

77 zone models apply the simple quasi-dimensional concept to represent the actual geometry of three-

78 dimensional (3-D) combustion chambers. The computational domain is divided into different zones

based on temperature inhomogeneity and chemical kinetics is then integrated into these zones

separately. Incorporation of comparatively large chemical mechanisms into multi-zone models is still

practical in terms of computational runtime [13-15]. These models perform reasonably well in

predicting the temporal pressure and heat release rate (HRR) profiles and the exhaust $\mathrm{NO}_{\mathrm{x}}$ and sulfur

oxides $\left(\mathrm{SO}_{\mathrm{x}}\right)$ levels. However, the in-cylinder flow field is not resolved, prohibiting the simulation of scavenging process which plays an important role to determine the marine engine performance. Due to the absence of the flow field, Cordtz et al. [15] implemented a mixing constant and calibrated the value based on exhaust nitrogen monoxide (NO) concentrations for the different engine speeds to account for the effects due to air-fuel mixing. Nevertheless, this reduces the robustness of the model.

88 In addition to this, multi-zone models do not provide detailed information regarding fuel spray development as well as spatial distribution of the flame and emissions. Although implementation of multi-dimensional computational fluid dynamics (CFD) models is more computationally expensive,

91 it is more robust and useful in providing details of the in-cylinder phenomena [2,16-19]. For

92 instance, Andersen et al. [16] performed CFD analyses of the scavenging process in the 4T50ME-X

93 test engine at MAN Diesel \& Turbo. Their CFD models considered the full engine geometry

94 including a moving piston and valve combined with time resolved measurements as boundary and

95 initial conditions. The ignition/combustion process was not simulated and a transport equation for a 
passive scalar was solved to evaluate the mixing of burned gases with the fresh air. Sigurdsson et al.

97 [17] also performed CFD analysis of the scavenging and heat transfer processes for the same test engine. In order to reduce computational expenses, a $12^{\circ}$ sector domain was used, considering one of the thirty scavenge ports. Therein, the main focus was to simulate the scavenged flow and heat transfer in the test engine but not the pollutant formation. Hence, the combustion process was simulated by implementing a time dependent heat source based on the experimentally determined HRR. 3-D CFD investigation of ignition/combustion and pollutant formation events in large, lowspeed uniflow-scavenged marine engines remains rare.

Numerical works which are closer to such application can be attributed to combustion modelling of four-stroke, medium-speed, direct injection marine diesel engines presented by Kilpinen [2], Kaario et al. [18] and Taskinen [19]. Simple chemistry was used to simulate the fuel oxidation and combustion process. Chemical equilibrium or partial equilibrium assumptions were applied to estimate formation of hydroxyl $(\mathrm{OH})$, hydrogen atom $(\mathrm{H})$ and oxygen atom $(\mathrm{O})$ which are pertinent to pollutants formation e.g. the NO formation $[2,18,19]$. However, in the flame zone, $\mathrm{O}$ and $\mathrm{OH}$ can be formed in quantities well over equilibrium. $\mathrm{NO}$ is formed via the Zeldovich reactions much more rapidly than it is when $\mathrm{O}$ atoms are in equilibrium. Calculation of super-equilibrium radical concentration becomes complex and must be integrated with the fuel oxidation kinetics [20]. Furthermore, soot precursor chemistry was not considered. Merely simple one- or two-step soot model were applied, based on the assumption that soot formation is direct decomposition from fuel species. Although this approach is proven to successfully capture the exhaust soot quantity, such validation does not guarantee that the in-cylinder soot level is correctly estimated. Comparisons of numerical results from the literature also show that the peak to exhaust soot levels vary significantly, depending on the soot precursor chemistry and soot model implemented $[21,22]$. Indeed, the performance of simple soot modelling approach in simulating the local soot volume fraction (SVF) 
120 in high-pressure environment is rarely validated. Such soot history is however, an important input to compute the soot radiative heat loss and soot deposition. Coupling of chemical kinetic mechanism and a revised phenomenological multi-step model can be promising for the prediction of SVF at high pressure and for the estimation of the variation of SVF with respect to ambient pressure levels. The model validation nonetheless was based on soot measurements of n-heptane spray combustion [23]. The soot model parameters may not be applicable to predict the soot quantity in diesel spray flames. Set against this background, the novelty of the present work consists of developing a skeletal 127 chemical kinetic mechanism which is computationally efficient for 3-D CFD large bore marine engine simulations yet sufficiently comprehensive to include species essential for pollutant formation predictions. In addition, the current work further validates and optimises the revised phenomenological multi-step soot model proposed by the authors [23] using laser extinction measurements of diesel soot at various ambient pressure levels [3]. By incorporating the in-house 132 chemical mechanism, optimised soot model parameter as well as turbulence /velocity fields obtained 133 from previous scavenge flow simulations [17], the present work aims to numerically investigate in134 cylinder phenomena in a large, low-speed uniflow-scavenged marine diesel engine, operating at full 135 load condition where optical measurements are not available. The flame development, soot 136 formation/oxidation processes and the associated soot radiative heat loss are of main interests here. The remainder of the paper is structured such that the diesel surrogate fuel models used in this work are first described, with an emphasis on the development and validation of the new skeletal n-heptane model. The subsequent section of the paper details the CFD formulation and setup. This is followed by the descriptions of the initial condition and mesh configuration for both constant volume chamber and marine engine. Model validation based on the optical measurements is performed next. In the consequent section, numerical analysis of the in-cylinder events of the marine diesel engine is presented. Key conclusions from the work are highlighted in the final section of the paper. 


\section{$144 \quad 2 . \quad$ Numerical formulation and setup}

\section{$145 \quad 2.1 \quad$ Diesel surrogate fuel models}

146 Recent experimental and numerical studies have highlighted that aromatic and/or cycloparaffin

147 chemistries have to be considered in the initial fuel composition in order to simulate the soot

148 precursor formation [24-26]. It has been demonstrated in the simulations where the flame

149 temperature changes, diesel fuel surrogate models which neglect aromatic/cycloparaffin chemistries

150 in the initial fuel composition failed to replicate the variation of SVF [25,26]. This is attributed to the

151 absence of soot precursor formation pathways through the oxidation of aromatic/cycloparaffin

152 compounds and these reaction rates are strongly dependent on the flame temperature. In such cases,

153 implementation of multi-component chemical mechanisms which consider aromatic/cycloparaffin

154 chemistries in the initial fuel composition is essential [25]. Exclusion of these chemistries from the

155 initial fuel composition is however acceptable when the flame temperature does not vary

156 significantly among the cases. With the use of a single-component $n$-heptane chemical mechanism,

157 Vishwanathan and Reitz [27] successfully captured the change of SVF with respect to the variations

158 of injection parameters such as injection pressure, nozzle diameters and fuel mass delivered.

159 Variations of these parameters do not affect the thermochemical state and the resulting flame

160 temperatures in all their test cases are similar. In the present work, the ambient pressure is the main

161 varying parameter and such variation is not expected to influence the flame temperature

162 significantly. As such, n-heptane chemical mechanisms which generally have relatively small

163 chemistry size are of main interests here in order to minimise the computational cost, particularly for

164 the marine diesel engine simulations.

Different skeletal n-heptane mechanisms were developed in the past decades for the simulation of diesel engine combustion simulations. To-date, one of the most compact models was developed by Patel et al. [28]. Their mechanism which consists of 52 reactions with 29 species is 
adopted here. The current work also evaluates the performance of the 44 species and 68 species mechanisms which were constructed by Liu et al. [29] and Lu et al. [30], respectively. Apart from these, a 30 species mechanism is developed based on a further reduction of the skeletal model constructed by Pang et al. [31]. The first step in the mechanism reduction is removing species and

172 reactions involved in the formation to benzene ring. Based on the previous sensitivity study, spatial 173 and temporal evolution of Polycyclic Aromatic Hydrocarbon (PAH) formation and acetylene $\left(\mathrm{C}_{2} \mathrm{H}_{2}\right)$ 174 are identical in cases with high flame temperature of around $2700 \mathrm{~K}$ i.e. those operating without 175 engine gas recirculation (EGR) [23]. As such, $\mathrm{C}_{2} \mathrm{H}_{2}$ serves as a good candidate as soot precursor. 176 Seven species and twenty-three reactions involved in benzene ring formation are hence removed. 177 The second step is implementing the directed relation graph method with error propagation method 178 to identify the irrelevant species [32]. The targeted conditions include eight initial temperatures (650 $\mathrm{K}, 750 \mathrm{~K}, 850 \mathrm{~K}, 950 \mathrm{~K}, 1050 \mathrm{~K}, 1150 \mathrm{~K}, 1250 \mathrm{~K}$ and $1350 \mathrm{~K})$ and three equivalence ratios $(0.5,1.0$ and 2.0) at an initial pressure of 41.0 bar. Unimportant species and the associated reactions are then remains below $11.0 \%$ for initial temperatures of $950 \mathrm{~K}$ and below at all three equivalence ratios.

Performance of these four mechanisms in predicting IDTs and flame liftoff lengths is discussed in section 3.1.2, by comparing the associated simulation results against optical measurements presented by Pickett and Siebers [3]. 


\section{$2.2 \quad$ CFD submodels}

193 Diesel spray combustion simulation in this work is performed using the CFD commercial code, 194 STAR-CCM+ version 10 [33]. The Eulerian-Lagrangian framework is utilised to solve the two-phase 195 flow of diesel spray jet. Rosin-Rammler is applied to model the fuel droplet size distribution while 196 the Kelvin Helmholtz-Rayleigh Taylor (KH-RT) is implemented to simulate the secondary spray 197 breakup. The KH-RT model constant which governs the breakup rate, $B_{1}$ is set to 25 . This is calibrated based on the liquid penetration length (LPL) of the non-reacting spray case in the constant volume chamber. As such quantitative measurement is not available for the marine test engine setup, the same $B_{1}$ value is used in the baseline setup for the marine engine simulation. The effect of this parameter on overall spray combustion characteristics is then studied. In addition, the Ranz-Marshall correlation is implemented to calculate the droplet heat transfer with the surrounding gas phase. The diesel liquid properties are represented by those of n-tetradecane since the thermo-physical properties models reproduced the tangential velocity reasonably well. As the RNG $k$ - $\varepsilon$ model is by default not of this component deviate by only $8 \%$ when compared to those of diesel, among the fuel range of cyclohexane $\left(\mathrm{C}_{6} \mathrm{H}_{12}\right)$ to heneicosane $\left(\mathrm{C}_{21} \mathrm{H}_{44}\right)$ examined by Lin and Tavlarides [34]. The fuel droplet temperature used in each case is provided in Table 1.

The turbulent flow is modelled using the Unsteady Reynolds Averaged Navier-Stokes (URANS) method in both constant volume combustion chamber and marine engine simulations. In the former, standard $k-\varepsilon$ model is used and the value of $C_{l}$ is increased from 1.44 to 1.55 according to its approximation for round jets [23]. On the contrary, Sigurdsson et al. [17] found that standard $k-\varepsilon$ model is not appropriate to simulate the tangential velocity profiles of the uniflow scavenging process in the present marine test engine. Instead, comparisons of experimental and numerical results showed that both the Renormalisation Group (RNG) $k-\varepsilon$ and $k-\omega$ Shear Stress Transport (SST) available in the code, the $k$ - $\omega$ SST model is applied in the marine engine simulations. The well- 
stirred reactor model is implemented, by which the sub-grid turbulence-chemistry interaction effects are not considered. Chemical mechanisms are incorporated into the CFD code through the implementation of DARS-CFD toolkit which manages the complex chemical reactions [33].

Soot models which are more computationally affordable and broadly applied in CFD simulations and industrial-level design of diesel engines are of main interests here. Two transport equations are solved for soot mass fraction and soot particle number density in the model [35].

222 Detailed descriptions of the model can be found in the previous work [23,25]. Here, only the expressions for the soot surface growth rate, $\omega_{s g}$ (in the unit of $\mathrm{kmol} \cdot \mathrm{m}^{-3} \cdot \mathrm{s}^{-1}$ ) are provided.

$\omega_{s g, c o n v}=6000 \cdot \exp \left(\frac{12100}{T}\right) \cdot S_{\text {soot }}^{0.5} \cdot\left[C_{2} H_{2}\right]$

$\omega_{\text {sg, rev }}=14 \cdot\left(\frac{P}{\mathrm{P}_{\text {ref }}}\right)^{1.4} \cdot \exp \left(\frac{12100}{T}\right) \cdot S_{\text {soot }}^{0.5} \cdot\left[C_{2} H_{2}\right]$

Here, $\left[\mathrm{C}_{2} \mathrm{H}_{2}\right]$ is the molar concertation of acetylene. $T$ and $P$ denote the local temperature and pressure, respectively. $S_{\text {soot }}$ is the soot specific surface area which is an important parameter for soot surface growth process. The subscripts conv and $r e v$ in equations 1 and 2 represent the conventional and revised surface growth submodels, respectively. Lastly, $P_{r e f}$ is the reference pressure which is set to 1.0123 bar. Development and validation of the revised model was carried out in the previous work using an open-source CFD code [23]. In the present work, the reaction rates of the surface growth process described by equations (1) and (2) are implemented using user-defined field functions. measurement revealed that the radiative heat loss is not significant in this setup [36]. In the marine diesel engine test case, greater amount of fuel is delivered through a larger nozzle diameter at lower injection pressure. In addition, the flame size is expected to be much larger due to the larger nozzle 
239 diameter. Furthermore, no EGR is considered and the engine operates at full load condition in the

240 selected test case. The soot formation rate is expected to be higher and may lead to greater soot

241 radiative heat loss. Soot radiative heat loss calculation is hence performed using the discrete

242 ordinates method (DOM). The Planck mean absorption coefficient, $\kappa_{\text {soot }}$ (in the unit of $\mathrm{m}^{-1}$ ) as shown

243 in equation (3) is used to define the soot absorption coefficient [37-39].

$\kappa_{\text {soot }}=C_{0} \cdot S V F \cdot T$

$247 T$ is the local temperature and $C_{0}$ is a constant set to 1862 in the baseline setup [37]. Soot particles

248 are generally small and the scattering process is negligible. The scattering coefficient is hence

249 assumed equal to 0 . Gas radiation modelling is deliberately not considered such that the effects from

250 soot radiation alone can be identified. Wall temperatures of cylinder head, valve and piston are fixed 251 at $523 \mathrm{~K}, 873 \mathrm{~K}$ and $673 \mathrm{~K}$, respectively [17]. The liner temperature is set to $423 \mathrm{~K}$ which is an 252 averaged value of the linear profile measured experimentally and used by Sigurdsson et al. [17]. All

253 the walls are assumed gray with emissivity equal to 0.8 . The order of the DOM approximation is 254 listed as an Sn approximation. The number of rays is set to S4 approximation in the present work. 255 Based on a sensitivity study, this configuration produces results which are sufficiently close to that of 256 higher number of rays in terms of heat transfer as well as formation of NO and soot.

\subsection{Initial condition and mesh configuration}

\subsubsection{Constant volume chamber}

260 Model validation in this work uses experimental measurements of transient diesel sprays in a constant volume chamber, where the injector is mounted at the centre of the chamber $[3,4]$. Operating conditions and the corresponding injection profiles of the test cases are summarised in 
263 Table 1. In the non-reacting spray test case, $\mathrm{O}_{2}$ mole fraction is set to zero. The ambient temperature 264 and density in the non-reacting case are fixed at $900 \mathrm{~K}$ and $22.8 \mathrm{~kg} / \mathrm{m}^{3}$, respectively [4]. As depicted 265 in Table 1, the ambient temperature of $900 \mathrm{~K}$ is close to that in the reacting cases while the ambient 266 density of $22.8 \mathrm{~kg} / \mathrm{m}^{3}$ in this test case is an intermediate value among those in reacting test cases.

267 Likewise the initial conditions used in the experiment [3], the ambient temperature is fixed at $950 \mathrm{~K}$ 268 while the ambient densities are varied from $7.3,14.8$ to $30.0 \mathrm{~kg} / \mathrm{m}^{3}$. This corresponds to ambient pressure of 18.6, 38.6 and 80.0 bar, respectively. A numerical experiment is also carried out in which the initial pressure is further increased to 150.0 bar, with the aim to imitate the pressure level in the marine diesel engine. For all the reacting and non-reacting cases, the initial velocity is set to zero.

272 The initial turbulence kinetic energy is set to $0.735 \mathrm{~m}^{2} / \mathrm{s}^{2}$, which is based on an estimation of the 273 experiment, while the initial turbulence dissipation rate is set to $5.67 \mathrm{~m}^{2} / \mathrm{s}^{3}$ [23].

275 Table 1. Operating conditions and injection profiles for non-reacting and reacting sprays.

\begin{tabular}{lcccccc}
\hline & \multicolumn{5}{c}{ Constant volume chamber } & Marine engine \\
\hline$\left[\mathrm{O}_{2}\right]$ & 0 & $21 \%$ & $21 \%$ & $21 \%$ & $21 \%$ & $21 \%$ \\
$\rho_{t=0}\left(\mathrm{~kg} / \mathrm{m}^{3}\right)$ & 22.8 & 7.3 & 14.8 & 30.0 & 56.3 & 57.3 \\
$\mathrm{P} t=0[\mathrm{bar}]$ & 67 & 19.6 & 38.6 & 80.0 & 150.0 & 152.9 \\
$\mathrm{~T} t=0[\mathrm{~K}]$ & 900 & 950 & 950 & 950 & 950 & 924 \\
Orifice diameter $(\mathrm{mm})$ & 0.09 & 0.1 & 0.1 & 0.1 & 0.1 & 1.05 \\
Fuel mass delivered $[\mathrm{mg}]$ & 13.77 & 17.8 & 13.5 & 13.94 & 13.94 & 44.6 \\
Injection duration $[\mathrm{ms}]$ & 6.1 & 6.5 & 4.9 & 4.87 & 4.87 & 31.2 \\
Fuel temperature $(\mathrm{K})$ & 373 & 436 & 436 & 436 & 436 & 400 \\
Minimum cell size $[\mathrm{mm}]$ & & & 0.25 & & & 2.5 \\
Time-step size $[\mu \mathrm{s}]$ & & & 0.4 & & & 4.0 \\
\hline
\end{tabular}

A 2-D axisymmetric mesh is employed here in which the axial length is adjusted to reproduce the actual combustion chamber volume which has a cubical shape with side lengths of $108 \mathrm{~mm}$. A coarser mesh up to $4.0 \mathrm{~mm}$ is used outside the spray combustion region in order to reduce the computational cost while a cell size of $0.25 \mathrm{~mm}$ is used for both radial and axial directions within the 
spray combustion region. Ignition and combustion occur at a further upstream location towards the injection tip in test cases at ambient pressure of 38.6 bar and above. For these cases, the $0.25 \mathrm{~mm} \mathrm{x}$ $0.25 \mathrm{~mm}$ grid is constructed up to $70 \mathrm{~mm}$ from the injection tip. This is shown in Figure 2(a). The resulting computational grid has 23030 cells. At low ambient pressure of 18.6 bar, the ignition occurs associated, maximum local Courant number is found to be lower than 0.4. later and at a further downstream location. The $0.25 \mathrm{~mm} \times 0.25 \mathrm{~mm}$ region is hence extended along the spray axis to ensure the cell size is sufficiently fine to capture the combustion and flame propagation. The number of cells increases to 38640 . The time-step size is fixed at $0.4 \mu$ s and the

\subsubsection{Marine diesel engine}

The simulated engine is the MAN Diesel \& Turbo 4T50ME-X research engine. Details of the engine specification were provided by Sigurdsson et al. [17]. The simulations performed here consider only one engine cylinder and initiate from Top Dead Centre (TDC). The in-cylinder temperature and pressure at TDC in the current test case are set to $924 \mathrm{~K}$ and 152.9 bar, respectively, similar to those estimated in the experiment. The initial flow field and turbulence intensity are mapped from the previous work [17]. The in-cylinder swirl motion at TDC corresponds approximately to a solid body rotation with $21 \mathrm{~m} / \mathrm{s}$ near the wall and a no-slip condition is applied at each wall boundary. The turbulent kinetic energy has a maximum value of $10 \mathrm{~m}^{2} / \mathrm{s}^{2}$ at the centre of the cylinder and gradually decreases to $2.35 \mathrm{~m}^{2} / \mathrm{s}^{2}$ for cells adjacent to the walls. On the other hand, the specific dissipation rate has a rather uniform value of $299 \mathrm{~s}^{-1}$ throughout the bulk gas region and increases exponentially to a higher value of $69095 \mathrm{~s}^{-1}$ near the walls. The engine speed in this case is $123 \mathrm{rev} / \mathrm{min}$ and a sinusoidal function is used to define the movement of the piston during compression/expansion. Two injectors are fitted at each side in the cylinder and each of the injector consists of four nozzle holes with diameter of $1.05 \mathrm{~mm}$. The symmetry imposed by the two identical injectors allows 
a $180^{\circ}$ sector mesh to be used to represent half of the combustion chamber. The $180^{\circ}$ section of the combustion chamber provides sufficient domain space to resolve the injection/combustion process while retaining high level of computational efficiency. For simplicity, the piston, cylinder head and exhaust valve geometries are modelled using plane surfaces with sharp edges. However, care is taken, to ensure that the compression volume and the effective flow areas in the model are the same as in the physical engine [17]. Similar to the mesh configuration used in the constant volume chamber, the cell at the vicinity of spray combustion region is locally refined. For the mesh at TDC, the minimum isotropic cell size is $2.5 \mathrm{~mm}$ at the vicinity of the injection tip. Otherwise, a larger cell size of $5 \mathrm{~mm}$ is used. Towards each wall boundary, the mesh resolution is designed to be finer in an exponential manner in order to comply with the required $\mathrm{y}^{+}$values for the wall treatment of turbulence modelling [17]. Cells adjacent to each wall have a thickness of approximately $5.0 \times 10^{-3}$ $\mathrm{mm}$. The final computational grid consists of approximately 290,000 cells. Cross sections of the grid from top and side views can be found in Figure 2(b). The time-step size is fixed at $4.0 \mu$ s in the baseline setup. In general, the maximum Courant number is found to retain below 0.4, although there are spikes which reach 0.65 . A sensitivity study is performed in section 4.1.1 to evaluate the effects of spatial and temporal resolution on the numerical results.

\section{Constant volume chamber simulations}

323 The first part of this section demonstrates the comparisons of CFD simulation results against 324 experimental liquid and vapour penetration lengths. It is followed by the validation of the calculated 325 IDTs, liftoff lengths and averaged SVF of reacting sprays using measured data. The simulated fuel penetration length, IDT and liftoff length are defined by the same criteria used in the previous work [23]. Effects of ambient pressure on to flame structure and soot characteristics are then studied. 


\subsection{Numerical model validation}

\section{$330 \quad 3.1 .1 \quad$ Liquid and vapour penetration lengths}

331 In the present study, it is noticed that when a coarser mesh is used, the $C_{l}$ value of the standard $k-\varepsilon$ 332 model has to be increased to a higher value in order to match the experimental vapour penetration 333 length. In contrast, when a finer mesh is used, the value which is closer to the default value of 1.44 334 can be implemented. However, the number of cells increases and the associated computational 335 runtime increases unnecessarily. The cell size within the spray combustion region is thus fixed at $3360.25 \mathrm{~mm}$ for both radial and axial direction. Implementation of this spatial resolution produces 337 results which are close to those calculated using a cell size of $0.125 \mathrm{~mm}$. This cell size also 338 corresponds to the minimum cell size recommended by the Engine Combustion Network [40]. 339 Comparisons shown in Figure 3(a) reveal that the numerical model reproduces the experimental 340 liquid and vapour penetration lengths reasonably well. Although both penetration lengths show 341 minor discrepancies in the first $0.5 \mathrm{~ms}$, the simulated and experimental results agree with each other 342 at quasi-steady state. mechanisms. The maximum relative difference remains below $33 \%$ as compared to the experimental data, apart from that calculated using the 29 species mechanism. IDT in the 18.6 bar case calculated using the 29 species mechanism is more than two-fold greater as compared to the measurement. Due to the overestimated IDT, the flame stabilises at a further downstream location, yielding a relatively long liftoff length, as illustrated in Figure 3(c). This is partially attributed to the implementation of a surrogate single step reaction R1 to represent the cool-flame reactions. Cool-flame reactions are originally described by three reaction classes of heptylperoxy radical isomerisation $\left(\mathrm{C}_{7} \mathrm{H}_{15} \mathrm{O}_{2}=\right.$ 
$353 \mathrm{C}_{7} \mathrm{H}_{14} \mathrm{OOH}$ ), addition of $\mathrm{C}_{7} \mathrm{H}_{14} \mathrm{OOH}$ to $\mathrm{O}_{2}$ and isomerisation of $\mathrm{O}_{2} \mathrm{C}_{7} \mathrm{H}_{14} \mathrm{OOH}$. Also, a pressure 354 dependent reaction as expressed by R2 was absent from the 29 species mechanism [41].

At 18.6 bar, liftoff lengths predicted by the 30 and 44 species mechanisms are 21 and $11 \mathrm{~mm}$, respectively shorter than the experimental value. Nonetheless, both of these mechanisms calculate accurate liftoff lengths at higher ambient pressure levels. Liftoff lengths calculated using the 68 species mechanism show overall the best agreement, although they are consistently overestimated. Experimental IDT and liftoff length are not available for the 150.0 bar test case. Comparisons among the numerical results show that the IDTs and flame liftoff lengths do not vary significantly from one another at such high pressure. While the 29 species mechanism has the smallest chemistry size, this mechanism does not consist of $\mathrm{C}_{2} \mathrm{H}_{2}$ which is essential for soot formation modelling. Implementation of the larger two mechanisms, on the other hand increases the computational cost unnecessarily. For example, computational runtime required by the 44 and 68 species mechanisms are 1.5- and 2.2-fold longer than that of the 30 species mechanism in the 84 bar test case. Moreover, runtime required by the 29 and 30 species mechanisms has a difference of only 10\%. This shows that the use of the 30 species mechanism achieves a balance between computational efficiency and accuracy. This mechanism is henceforth selected for the subsequent soot modelling and marine engine simulations.

\subsubsection{Averaged soot volume fraction}

375 Performance of both conventional and revised multi-step soot models is evaluated on the basis of averaged SVF at several axial locations along the spray axis. The experimental data also serves as a 
377 reference to calibrate the soot model constant prior to simulating the SVF in the test cases where the 378 in-situ measurements are not available. The averaged SVF at each axial position is calculated using 379 equation (4),

where $r_{s}$ is the radius of the soot cloud at different axial locations. This corresponds with the definition for the experimental averaged SVF [3]. As shown in Figure 4(a), no soot formation is observed in the 18.6 bar experimental case. However, the conventional multi-step soot model overestimates the soot production at this ambient pressure. It is noticeable that, the overprediction of SVF is not entirely due to the underestimated liftoff length by the 30 species mechanism. Figure 4(a) also includes the averaged SVF calculated using the combination of 68 species mechanism and conventional multi-step soot model. The predicted soot formation remains noticeable. On the other hand, the revised soot multi-step model predicts averaged SVF values of lower than $1 \mathrm{ppm}$, regardless the use of the 30 or 68 species mechanism.

As illustrated by Figures 4(b) and (c), the conventional multi-step soot model predicts averaged SVF value in the 38.6 bar case but underestimates that in the 80.0 bar case. As a result, the associated peak averaged SVF merely increases by a factor of two. This increment is much lower than that recorded in the experiment, where the peak averaged SVF in the 80.0 bar case is approximately six-fold higher. Rise of the peak averaged SVF calculated by the revised soot model is approximately eight-fold, which is closer to the experimental observation. The overestimation of averaged SVF is attributed to narrower soot cloud in cases with higher ambient pressure [23]. As such, the integrated soot area is averaged by a shorter radius, yielding a higher averaged SVF. It is 
also noticed that absolute SVF values are not accurately predicted using the default model constant

values. This may be expected since the model constant values were calibrated to simulate SVF in nheptane spray combustion. Here, a parametric study is carried out for the surface growth submodel

constant, $C_{g}$. The parametric study shows that increasing the model constant value by a factor of two

produces better agreement with the experimental measurements in terms of peak averaged SVF.

405 Although the calculated and measured peak locations have a consistent discrepancy of approximately

$40630 \mathrm{~mm}$, the difference of peak locations is considered small relative to the large marine engine

407 cylinder which has a bore diameter of $0.5 \mathrm{~m}$ and a stroke of $2.2 \mathrm{~m}$. Using this model constant, the

408 peak averaged SVF is $300 \mathrm{ppm}$ at the 150 bar case. This is approximately fifteen-fold higher than

409 that predicted using the conventional model. Effects of ambient pressure on flame structure and soot

410 production are detailed in the following subsection.

\subsection{Effects of ambient pressure on flame structure and soot formation}

\subsubsection{Local temperature and equivalence ratio}

414 Figure 5 depicts the scatter plot of computational cells in temperature-equivalence space for four 415 cases with different ambient pressure levels. Each point on the scatter plot corresponds to a local 416 property. The local temperature, $T$ is directly extracted from the simulation results while the 417 equivalence ratio, $\phi$ value is computed based on the molar concentration of species with element $\mathrm{C}$, $418 \mathrm{H}$ and $\mathrm{O}$ using the equation (5),

$\phi=\frac{\sum_{i=1}^{N_{\text {species }}} 2 n_{C_{i}}\left[C_{i}\right]+\frac{1}{2} n_{H_{i}}\left[C_{i}\right]}{\sum_{i=1}^{N_{\text {species }}} n_{O_{i}}\left[C_{i}\right]}$ 
422 where $n_{C i}, n_{H i}$ and $n_{O i}$ are the numbers of $C, H$ and $O$ atoms, respectively, of the $i$-th species, while $423\left[C_{i}\right]$ is the concentration of the $i$-th species in $\mathrm{kmol} / \mathrm{m}^{3}$ [42]. In Figure 5, the ambient gas regime is 424 represented by low $T$-low $\phi$ data points while the region near the injector is characterised by low $T$ 425 high $\phi$ points. Points in between these two regions i.e. those with low $T$, variable $\phi$ correspond to 426 inert mixing between fuel and ambient gas. Different locations in the quasi-stationary diesel flame 427 structure proposed by Dec [43], including the rich premixed core and the outer diffusion flame which 428 is formed between the products of rich premixed combustion and the ambient gas are also indicated 429 in Figure 5. The reaction zone structure in all four cases is similar to a classical diffusion flame. The 430 maximum temperature occurs at $\phi$ of approximately unity in the diffusion flame. It is noticeable that

431 the maximum local temperature has a minor difference in these cases. The maximum local 432 temperature in the 150.0 bar case is approximately $50 \mathrm{~K}$ higher than that in the 18.6 bar case. On the 433 contrary to this, the $\phi$ values are found to increase with the rise of ambient pressure in the 434 temperature range of $1000 \mathrm{~K}$ to $2000 \mathrm{~K}$, within the rich premixed core region. The difference in $\phi$ 435 reduces within the diffusion flame where local temperatures are higher. As aforementioned, the 436 flame liftoff length reduces when the ambient pressure increases. This reduces the total amount of air 437 entrained into the fuel jet, yielding a relatively fuel-rich site. Figure 5 also highlights that the region with the $10 \%$ highest SVF at all test conditions consistently falls within the $\phi$ range of 1.6 to 2.0 and temperature range of 2200 to $2350 \mathrm{~K}$.

\subsubsection{Soot inception time and individual process rates}

442 Investigation of the effect of ambient pressure on soot formation focuses on the 38.6, 80.0 and 150.0 bar test cases where soot formation is pronounced. The first parameter to be studied is the soot onset.

444 Figure 6 depicts that the soot onsets occur at the peaks of the HRR during the premixed combustion (PMC) phase in all three cases. This shows good agreement with the experimental results presented 
446 by Singh et al. [9], in which revealed that considerable amount of diesel soot is detected at the peak 447 of HRR during the PMC phase. Rates of formation and oxidation of the quasi-steady diesel flame jet 448 at these three ambient pressure levels are plotted as a function of $\phi$ in Figure 7 [22]. As demonstrated 449 in Figures 7(a) and (b), both the nucleation and surface growth rates peak at $\phi$ of 1.5. The former 450 does not show significant difference in terms of peak values while the latter varies significantly with 451 the ambient pressure. This is attributed to the empirical expression as shown by equations 1 and 2. 452 The surface growth rate is a function of square root of $S_{\text {soot }}$ and ambient pressure dependence is taken 453 into account while the nucleation rate expression is independent from these parameters. These 454 collectively give rise to the surface growth rate as the ambient pressure increases. In addition, the 455 soot oxidation rates shown in Figure 7(c) peak at a lower $\phi$ close to 1.2 and the value increases with 456 ambient pressure. The oxidation rate is a linear function of $S_{\text {soot }}$. This in turn leads to a larger 457 variation of peak soot oxidation rate as compared to that of the surface growth rate. In these quasi458 steady diesel flame jet cases, the peak oxidation rates due to $\mathrm{OH}$ and $\mathrm{O}_{2}$ are found to be comparable. 459 In summary, this section shows that IDT and liftoff length at varying ambient pressure levels 460 in the constant volume chamber are successfully captured by the proposed models. This subsequently 461 leads to a reasonably accurate prediction of the averaged SVF. The onset of soot corresponds well 462 with the HRR peak of the premixed combustion phase. This is consistent with the experimental 463 results obtained by Singh et al. [8]. Apart from these, the simulated temperature and $\phi$ agree well 464 with experimental results from the literature.

\section{Marine diesel engine simulations}

467 Upon the model validation in section 3, the numerical models are hereafter applied to investigate the in-cylinder phenomena under marine diesel engine-like conditions. Effects of temporal and spatial resolutions as well as different physical models are first evaluated through a sensitivity study. 
470 Section 4.2 subsequently emphasises on the investigation of the associated flame development, 471 emissions formation and heat transfer processes.

\section{$473 \quad 4.1 \quad$ Sensitivity studies}

$474 \quad 4.1 .1 \quad$ Computational cell and time-step sizes

475 Figure 8(a) depicts comparisons of pressure and HRR curves generated using different computational 476 cell and time-step sizes. As can be seen, although the overall pressure and HRR curves are 477 reasonably estimated using a larger time-step size of $8.0 \mu \mathrm{s}$, a sharp spike in the HRR plot is 478 observed. This is due to a steep pressure rise near ignition. On the other hand, results generated using $4794.0 \mu \mathrm{s}$ in the baseline setup are sufficiently close to those using $2.0 \mu \mathrm{s}$. Results in Figure 8(a) also 480 show that the HRR profile generated using the computational mesh without local refinement 481 diverges from experimental data, showing a second rise at approximately 17.5 CAD ATDC. This is 482 attributed to the stretching of cells in the axial direction. In this case, the injection period falls between 1.2 and 23 CAD ATDC. When local refinement is not applied, the cell size in the axial 484 direction is elongated to approximately $8 \mathrm{~mm}$ at 17.5 CAD ATDC. In order to replicate the experimental HRR curve, local refinement is applied such that the cell size within the fuel spray region is retained below $5 \mathrm{~mm}$ during the injection period.

\subsubsection{Physical models}

489 Comparisons to the experimental data provided in Figure 8(b) show that the simulated pressure rise 490 starts 1.0 crank angle degree (CAD) in advance and the calculated peak pressure is $1.7 \%$ lower. A sensitivity study is carried on the $B_{l}$ value of the KH-RT model which normally varies from 1.73 to 49260 , depending on the injection specifications. Increasing this value leads to slower breakup and 493 subsequently the ignition delay period could become longer. Nonetheless, as the $B_{l}$ value is 
494 increased by a factor of two to 50, prediction of IDT is not improved but a second rise in the HRR 495 curve is observed. This is attributed to the slow breakup. Relative large amount of fuel droplet exists 496 and starts to burn only at a later CAD. HRR calculated using $B_{1}$ value of 25 in the baseline setup 497 starts to form a 'plateau' which gives a similar shape as shown by the experimental data. This value 498 is henceforth fixed in the subsequent simulations.

499

500

501

502

Figure 10 depicts the $T-\phi$ map for the diesel spray flame at 3.0 CAD ATDC. At this CAD, the flame has fully developed but has not impinged on the piston surface. The overall $T$ - $\phi$ scatter plot 
agrees well with that observed for the quasi-steady diesel spray flame jet in the constant volume chamber. Akin to the quasi-stationary spray jet, the maximum temperature is around $2850 \mathrm{~K}$. However, there exists a region which is richer. The total fuel amount delivered through the four nozzles is much greater than that in the constant volume chamber case. In addition, the maximum

522 injection velocity is approximately two-fold lower in the marine diesel engine case, yielding a 523 substantial decrease in liftoff length [3]. The liftoff length in the marine diesel engine case is $1.3 \mathrm{~mm}$ which is negligible relative to the flame size, allowing only a small amount of air to entrain into the upstream of the fuel jet. Figure 10 also highlights that soot particles distribute across a wider range of $\phi$ values. High soot concentration is observed at local temperature of $1300 \mathrm{~K}$ and $\phi$ of 1.5 to approximately 8 . This is different from that observed in the quasi-steady diesel spray jet. The maximum SVF here is found to be four-fold higher than that in the quasi-steady diesel jet. This is attributed to the greater fuel amount as well as the higher equivalence ratio due to the shorter liftoff length as discussed earlier.

Figures 11(a) and (b) provide the scatter plot of $\phi$ against nucleation and surface growth rates, respectively. Both peak nucleation and surface growth rate values in the two test conditions are in the same order of magnitude. It is noted that the nucleation rates in both of these high swirling flow engine and quasi-quiescent constant volume chamber cases are distributed within the identical region. This process happens at upstream of the flame and is less influenced by flow. On the other hand, the surface growth rate is more broadly distributed since this process occurs at a further downstream location and is affected by the swirling flow. In parallel with the formation processes, soot oxidation occurs. Figure 11(c) illustrates the oxidation rates in both cases. Here, the peak oxidation rate has a much higher value in the engine case and the oxidation rate is mainly dominated by that due to $\mathrm{O}_{2}$. It is worth mentioning that this pattern retains until approximately 17.5 CAD ATDC. In between 17.5 and $22 \mathrm{CAD}$ ATDC, the $\mathrm{OH}$ and $\mathrm{O}_{2}$ oxidation rates become comparable. 
542 Thereafter, the $\mathrm{OH}$ oxidation rate dominates. This can be attributed to the consumption of oxygen at 543 the vicinity of the soot cloud, while the production of $\mathrm{OH}$ continues until the combustion ends.

\subsubsection{Spatial and temporal evolution of combustion products}

546 The top view of resampled volume of $\mathrm{CH}_{2} \mathrm{O}, \mathrm{OH}, \mathrm{C}_{2} \mathrm{H}_{2}$ and $\mathrm{SVF}$ generated in STAR-CCM version

54710 is illustrated in Figure 12. All the layers are semi-transparent to allow inspection of the changes of 548 concentration as they develop during the injection period. The outline represents the edge of the 549 cylinder, while the centreline is the cyclic boundary where the $180^{\circ}$ domain is revolved to full 550 cylinder to illustrate the in-cylinder event. For better visualisation, the image background where no 551 combustion products formed is presented as white. $\mathrm{CH}_{2} \mathrm{O}$ is monitored in Figure 12(a) to illustrate 552 the low temperature chemistry reaction zone. This compound is formed at the upstream of the flame 553 near the injector. The distribution of the $\mathrm{CH}_{2} \mathrm{O}$ extends as the combustion progresses but remains at 554 the same location throughout the combustion phase. This highlights that the low temperature 555 chemistry zone is not influenced by the flow. Figure 12(b) provides the $\mathrm{OH}$ distribution to indicate 556 high temperature, diffusion flame. On the contrary to the previous plot, the $\mathrm{OH}$ distribution extends 557 gradually along the spray direction. At approximately 12 CAD ATDC, it is apparent that the flame is 558 transported by the strong swirling flow. Thereafter, the flame is distributed within the entire 559 chamber. Figure 12(c) demonstrates the formation of soot precursors and surface growth species, $560 \mathrm{C}_{2} \mathrm{H}_{2}$. This can also be used to indicate the rich premixed core. As shown, it is located slightly 561 further downstream as compared to the $\mathrm{CH}_{2} \mathrm{O}$ distribution. The volume of the $\mathrm{C}_{2} \mathrm{H}_{2}$ cloud is rather 562 consistent. At 20 CAD ATDC, the cloud size grows due to absence of $\mathrm{O}_{2}$ at the vicinity of the fuel 563 rich region. This can better be explained with the total rate of production of $\mathrm{C}_{2} \mathrm{H}_{2}$ provided in Figure 564 13. Positive and negative values indicate formation and oxidation of $\mathrm{C}_{2} \mathrm{H}_{2}$, respectively. As shown, 565 the rate of production fluctuates until 13 CAD ATDC due to a competition between the production 
and oxidation processes. Next the production process governs for the subsequent 6 CADs while oxidation process is negligible due to the absence of oxidiser. Corresponding to this, the $\mathrm{C}_{2} \mathrm{H}_{2}$ concentration increases, peaks at approximately 21 CAD ATDC and drops due to the end of fuel delivery. Lastly, the evolution of soot cloud is shown in Figure 12(d). Formation of the soot cloud is apparent at 3 CAD ATDC. Simulation results indicate that the soot cloud size in general is smaller 571 than the $\mathrm{OH}$ cloud size and the soot cloud is embedded by the diffusion flame. At approximately 12 572 CAD ATDC, the associated development is influenced by the swirling flow. Thereafter, the soot 573 cloud is broadly distributed.

Figure 14 demonstrates the temporal evolution of total soot mass and averaged NO 575 concentration calculated with and without considering soot radiation. For the NO formation 576 modelling, Zeldovich reactions are added to the fuel model. The Arrhenius parameters are originated 577 from GRI Mech 2.11 [44] and were used by Easley and Mellor [45] in their engine study. Results 578 show that the net soot mass calculated with soot radiation taken into account is lower at the 579 beginning but higher after approximately 27 CAD ATDC. As aforementioned, the soot particles 580 mainly exist in the fuel-rich region but not alongside the high temperature, diffusion flame in the 581 beginning of the combustion phase. The effect of soot radiation is hence insignificant on maximum 582 gas temperature. This implies that the soot oxidation rate does not change since the oxidation process 583 mainly occurs at the outer diffusion flame. In contrast, the local temperature within the rich premixed 584 core where soot formation is dominant becomes lower, leading to a decrease in soot formation rate. 585 As a result, a minor drop in net soot mass is observed for the beginning of the production stage when 586 soot radiation is considered. At the later stage, the temperature is smoothened through convection 587 induced by the strong swirling flow. The temperature and the oxidation rate of some regions become 588 lower, as compared to those calculated without considering soot radiation. This eventually leads to a 589 higher net soot mass production. It is also noticed that the soot formation in the current test case is 
different from those in other single main injection test cases which usually show a single peak value before declining. Here, soot is formed after the ignition but drops at approximately 7 CAD ATDC. The in-cylinder soot mass increases again at 15 CAD ATDC. This corresponds well with the net production of $\mathrm{C}_{2} \mathrm{H}_{2}$ as discussed earlier. Since the soot formation rate is a function of $\mathrm{C}_{2} \mathrm{H}_{2}$ molar concentration, the soot production profile is strongly influenced by the $\mathrm{C}_{2} \mathrm{H}_{2}$ formation and oxidation. Similar pattern is observed for soot mass profile calculated using the conventional soot model but the peak of total soot mass formed is approximately sixteen-fold lower.

The NO concentration profile is identical to those from the literature i.e. it increases and becomes stagnant. When the conventional soot model is applied, the overall SVF is much lower, yielding a decrease in the maximum soot absorption coefficient by a factor of approximately fourteen. The associated soot radiation hence has almost no impact on the NO concentration prediction. As can be seen, the NO level is lower when the soot radiation model is coupled with the revised soot model. A relative difference of approximately $7.7 \%$ is observed at 40 CAD ATDC when the NO formation is saturated. As aforementioned, soot radiation does not have an impact on the diffusion flame temperature where NO is formed. Therefore, the averaged NO production is not significantly influenced. A decrease in the overall temperature at the later phase of combustion leads to a more noticeable drop in NO levels. At 90 CAD ATDC, the averaged NO concentration estimated using the baseline setup is $1554 \mathrm{ppm}$ which is approximately 1.5 -fold greater than the measurement. It is noticed that the averaged NO concentrations are consistently overestimated when different sets of Arrhenius parameters are applied. The results generated using the GRI Mech 3.0 [44] is slightly lower at $1510 \mathrm{ppm}$ while that calculated with Arrhenius parameters proposed by Tao [46] is 1.8-fold greater than the experimental concentration. Overestimations of the NO value can be attributed to two reasons. Firstly, in this two-stroke engine, a part of the supplied fresh air bypasses the cylinder during the scavenging process and dilutes the outgoing exhaust gases. As compared to 
614 the averaged NO concentration recorded at 90 CAD ATDC when the exhaust valve is still closed, the measured exhaust concentration is lower due the dilution effect. Besides this, gas radiation is not taken into account in the current work. Important radiating gases, carbon dioxide and water vapour are formed closer to the formation of NO. The associated radiation effect is expected to be substantial on the peak temperature and hence the overall NO formation.

\subsubsection{Heat transfer}

621 The total heat transfer is shown in Figure 15. Heat transfer calculated with and without soot radiative 622 heat loss taken into consideration is compared. The spikes in the beginning of the simulation shown 623 in Figure 15 are due to the steep temperature gradients between the in-cylinder charge and walls 624 introduced by the initial conditions. They do not carry any physical meaning. A comparison of the total heat transfer calculated when both convective and soot radiative heat losses are taken into account to that where only convective is considered suggests that the former could be $30 \%$ higher.

627 Yet, the heat losses are relatively low, compared to those in automotive engines. This is consistent 628 with the numerical results obtained by Sigurdsson et al. [17]. It is also noted that the difference of 629 heat transfer is dependent on the formation period of the in-cylinder soot. All the heat transfer profiles appear to be similar after approximately 35 CAD ATDC, where the soot is significantly oxidised. Figure 15 also shows the effect of SVF level on the total heat loss. When the conventional soot model is used, the associated maximum total heat transfer drops to $11 \%$ higher than that in the 633 baseline case.

Different values have been suggested in the literature for the constant in the Planck mean absorption expression, $C_{0}$. Here, the sensitivity of the absorption coefficient on relevant processes is assessed, by varying the $C_{0}$ value from 1307 [38] to $2370 \mathrm{~m}^{-1} \mathrm{~K}^{-1}$ [39]. These two values are approximately $30 \%$ lower and higher, respectively than the one used in the baseline setup. For the 
tested values, no significant difference is observed for net soot mass, averaged NO concentration and total heat transfer (not shown). Also, it is noteworthy that a function of scattering-to-absorption ratio and soot refractive index is used to quantitatively relate the optical thickness to SVF [3]. The quantitative relationship is hence affected by uncertainties in the soot optical properties. If the soot 642 refractive index suggested by Williams et al. [47] is used to relate the optical thickness to SVF, all 643 the current SVF will have to be multiplied by a factor of 0.56 [40]. However, the sensitivity study of the Planck mean absorption coefficient may have indicated that a decrease of within the same order of magnitude in SVF values is not influential to the net soot mass, averaged NO concentration and total heat transfer process for this combustion system. Hence, the multiplication is not carried out

647 here. With the current SVF values, a higher possible soot radiative loss is estimated.

\section{Conclusions}

This work investigates combustion and soot formation processes in a constant volume chamber and a marine diesel engine. A skeletal n-heptane mechanism is developed for this purpose. The new skeletal mechanism has a compact size of 30 species with 68 reactions, yet it performs well in predicting the IDT and liftoff length under the tested conditions, apart from that at 18.6 bar. The fuel model allows direct coupling with a $\mathrm{SO}_{\mathrm{x}}$ mechanism [15] and a more comprehensive $\mathrm{NO}_{\mathrm{x}}$ mechanism since the fuel model includes essential radicals such as $\mathrm{O}, \mathrm{H}$ and $\mathrm{OH}$ for their reactions.

Reasonably good agreement has also been achieved between the simulated and experimental peak averaged SVF at varying ambient pressure levels in the constant volume chamber. This also indicates that the assumptions to exclude the PAH in the initial fuel composition and to apply single component fuel models are valid when the flame temperatures do not vary significantly among the test cases. The current results also show that equivalence ratio values within the rich premixed core region increases with the ambient pressure due to the drops of liftoff lengths. 
The validated chemical and soot models are subsequently coupled with the turbulence intensity and velocity fields calculated from previous work [17] in order to simulate in-cylinder combustion and pollutant formation in a uniflow scavenged, large marine diesel engine, operating at a heavily sooting condition where the optical measurements are not available. Spatial distribution of $\mathrm{OH}$ and soot particles are utilised to explain the effects of soot radiation. This provides insights and a better understanding on the aforementioned processes. For this test case, the simulated pressure and HRR results agree with the experimental data, although the simulated pressure rise starts 1.0 CAD in advance and the calculated peak pressure is $1.7 \%$ lower. The ignition site and the diesel flame jet are found forming close to the injection tips. This deteriorates the air entrainment to the fuel-rich region.

671 As a result, the associated local equivalence ratio and SVF values appear to be higher as compared to 672 those under similar test condition in the constant volume chamber.

The total heat transfer to the walls calculated when soot radiative heat loss is taken into account is approximately $30 \%$ higher than that where only convective heat loss is considered. Yet, the total heat losses are relatively low, compared to those in automotive diesel engines. Besides this, 676 the overall effect on the net soot mass production is minor. When the NO formation is saturated, the 677 averaged concentration is approximately $7.7 \%$ lower. Concentrations computed using Arrhenius 678 parameters proposed in the GRI Mech mechanisms [44] are found closer to the measurement, although they remain approximately 500 ppm higher. The overestimation can be attributed to effects of fresh air dilution and the absence of gas radiation. Current results also show neither increasing nor decreasing the soot absorption coefficient by $30 \%$ from the baseline setup is found influential to NO, soot mass and heat transfer.

The numerical model developed in this work is expected to serve as an important prerequisite to study different phenomena in this combustion system. For instance, by integrating gas radiation model on top of the current one, effects of gas radiation on heat transfer and emissions formation can 
be evaluated. Besides that, by coupling $\mathrm{SO}_{\mathrm{x}}$ mechanism into the fuel model, temporal and spatial $\mathrm{SO}_{\mathrm{x}}$

and sulphuric acid distribution can be identified. The latter is particularly significant for studying the

acid condensation and corrosion rates as heavy fuel oil which is commonly used in marine diesel

engines contains certain amount of sulfur [15].

\section{Acknowledgement}

692 The authors gratefully acknowledge funding from the Strategic Research Council of Denmark and 693 MAN Diesel \& Turbo A/S through the RADIADE project. The authors also thank Eric Baudoin, 694 Stefan Mayer and Simon Matlok (from MAN Diesel \& Turbo A/S) for valuable discussions.

695 Technical assistance provided by Hiew Mun Poon (from The University of Nottingham Malaysia 696 Campus) in the mechanism reduction is also much appreciated.

References

699

1. Imperato M, Kaario O, Sarjovaara T, Larmi M, Split fuel injection and Miller cycle in a largebore engine. Appl Energy 2016;162:289-97.

2. Kilpinen P. Optimization of a simplified sub-model for NO emission prediction by CFD in large 4-stroke marine diesel engines. Fuel Process Technol 2010;91 218-28.

3. Pickett LM, Siebers DL, Soot in diesel fuel jets: effects of ambient temperature, ambient density, and injection pressure. Combust Flame 2004;138:114-35.

4. Nerva J-G, Genzale CL, Kook S, Garcia-Oliver JM, Pickett LM, Fundamental spray and combustion measurements of soy methyl-ester biodiesel. Int J Engine Res 2012;14:373-90.

5. Zhang J, Jing W, Roberts WL, Fang T, Soot temperature and KL factor for biodiesel and diesel spray combustion in a constant volume combustion chamber. Appl Energy 2013;107:52-65. 
6. Payri R, Salvador FJ, Manin J, Viera A, Diesel ignition delay and lift-off length through different methodologies using a multi-hole injector. Appl Energy 2016;162:541-50.

7. Jeon J, Park S, Effects of pilot injection strategies on the flame temperature and soot distributions in an optical CI engine fueled with biodiesel and conventional diesel. Appl Energy 2015;160:581-91.

8. Jeon J, Kwon SI, Park YH, Oh Y, Park S, Visualizations of combustion and fuel/air mixture formation processes in a single cylinder engine fueled with DME. Appl Energy 2014;113:294301.

9. Singh S, Reitz RD, Musculus MPB, 2-Color Thermometry Experiments and High-Speed Imaging of Multi-Mode Diesel Engine Combustion. SAE Paper 2005-01-3842:2015.

10. Hult J, Matlok S, Mayer S, Particle image velocimetry measurements of swirl and scavenging in a large marine two-stroke diesel engine. SAE Paper 2014-01-1173:2014.

11. Hult J, Matlok S, Mayer S, Optical diagnostics of fuel injection and ignition in a marine twostroke diesel engine. SAE Int J Engine 2014;7:2014-01-1448.

12. Herrmann K, von Rotz B, Schulz R, Weisser G, A "spray combustion chamber" facility for investigations in relation to large 2-stroke marine diesel engine combustion system optimization, Proc Int Symposium on Marine Engineering (ISME) Kobe, Japan, 2011.

13. Raptotasios SI, Sakellaridisa NF, Papagiannakis RG, Hountalas DT, Application of a multi-zone combustion model to investigate the NOx reduction potential of two-stroke marine diesel engines using EGR, Appl Energy 2015;157:814-23.

14. Andreasen A, Mayer S. Modeling of the oxidation of fuel sulphur in low speed two-stroke diesel engines. CIMAC Congress paper no 39:Bergen, Norway 2010.

15. Cordtz R, Schramm J, Andreasen A, Eskildsen SS, Mayer S. Modeling the distribution of sulfur compounds in a large two stroke diesel engine. Energy Fuels 2013;27:1652-60. 
16. Andersen FH, Hult J, Nogenmyr K-J, Mayer S, Numerical investigation of the scavenging process in marine two-stroke diesel engines, SAE Paper 2013-01-2647:2013.

17. Sigurdsson E, Ingvorsen KM, Jensen MV, Mayer S, Matlok S, Walther JH, Numerical analysis of the scavenge flow and convective heat transfer in large two-stroke marine diesel engines. Appl Energy 2014;123:37-46.

18. Kaario O, Larmi M, Tanner F, Comparing single-step and multi-step chemistry using the laminar and turbulent characteristic time combustion model in two diesel engines, SAE Paper 2002-01$1749 ; 2012$.

19. Taskinen $\mathrm{P}$, Modelling of spray combustion, emission formation and heat transfer in medium speed diesel engine, Tampere University of Technology, 2005.

20. Turns SR, An introduction to combustion: Concepts and applications. $3^{\text {rd }}$ ed. New Yok: McGraw-Hill International Edition; 2012.

21. Tao F, Reitz RD, Foster DE, Liu Y. Nine-step phenomenological diesel soot model validated over a wide range of engine conditions. Int J Therm Sci 2007;48:1223-34.

22. Pang KM, Ng HK and Gan S, Investigation of fuel injection pattern on soot formation and oxidation processes in a light-duty diesel engine using integrated CFD-reduced chemistry. Fuel 2012;96:404-18.

23. Pang KM, Jangi M, Bai X-S, Schramm J, Evaluation and optimization of phenomenological multi-step soot model for spray combustion under diesel engine-like operating conditions. Combust Theor Model 2015;19: $279-308$.

24. Kook S, Pickett L, Soot volume fraction and morphology of conventional, Fischer-Tropsch, coalderived, and surrogate fuel at diesel conditions. SAE Int J Fuels Lubr 2012;5:647-64.

25. Pang KM, Poon HM, Ng HK, Gan S, Schramm J, Soot formation modeling of n-dodecane and diesel sprays under engine-like conditions. SAE Paper 2015-24-2468:2015. 
26. Bolla M, Farrace D, Wright YM, Boulouchos K, Modelling of soot formation in a heavy-duty diesel engine with conditional moment closure. Fuel 2013;117:309 -25.

27. Vishwanathan G, Reitz RD, Application of a semi-detailed soot modeling approach for conventional and low temperature diesel combustion - Part I: Model performance. Fuel 2015; $757-70$.

28. Patel A, Kong SC, Reitz RD. Development and validation of a reduced reaction mechanism for HCCI engine simulations. SAE Paper 2004-01-0558; 2004.

29. Liu S, Hewson JC, Chen JH, Pitsch H, Effects of strain rate on high-pressure nonpremixed nheptane autoignition in counterflow, Combust Flame 2004;137:320-39.

30. Lu T, Law CK, Strategies for mechanism reduction for large hydrocarbon: n-heptane. Combust Flame 2008;154:153-63.

31. Pang KM, Ng HK, Gan S, Development of an integrated reduced fuel oxidation and soot precursor formation mechanism for CFD simulations of diesel combustion, Fuel 2010;90:290214.

32. Poon HM, Ng HK, Gan S, Pang KM, Schramm J, Evaluation and development of chemical kinetic mechanism reduction scheme for biodiesel and diesel fuel surrogates SAE Int J Fuels Lubr 2013;6:2013-01-2630.

33. CD-adapco, STAR-CCM+® Documentation, Version 10.02, User Guide 2015.

34. Lin R, Tavlarides LL. Thermophysical properties needed for the development of the supercritical diesel combustion technology: Evaluation of diesel fuel surrogate models. J Supercrit Fluids $2012 ; 71: 136-46$.

35. Leung KM, Lindstedt RP, Jones WP, A simplified reaction mechanism for soot formation in nonpremixed flames, Combust Flame 1991;87:289-305. 
36. Skeen S, Manin J, Pickett L, Dalen K, and Ivarsson A, Quantitative spatially resolved measurements of total radiation in high-pressure spray flames, SAE Paper 2014-01-1252;2014.

37. Abraham J, Magi, V, Application of the discrete ordinates method to compute radiant heat loss in a diesel engine, Numerical Heat Transfer, Part A 1997;31597-610.

38. Brookes SJ, Moss JB, Predictions of soot and thermal radiation properties in confined turbulent jet diffusion flames. Combust Flame 1999;116:486 -503.

39. Widmann JF, Evaluation of the planck mean absorption coefficients for radiation transport through smoke. Combust Sci Technol 2003;175:2299-308.

40. Engine Combustion Network. Available at http://www.sandia.gov/ecn/

41. Vishwanathan G, Reitz RD, Numerical predictions of diesel flame lift-off length and soot distributions under low temperature combustion condition. SAE Paper 2008-01-1331;2008.

42. Bergman, M., Golovitchev, V.I., Application of Transient Temperature vs. Equivalence Ratio Emission Maps to Engine Simulations, SAE paper 2007-01-1086;2007.

43. Dec JE, A conceptual model of DI diesel combustion based on laser-sheet imaging, SAE Paper $970873 ; 1997$.

44. Bowman CT, Hanson RK, Davidson DF, Gardiner Jr. WC, Lissianski V, Smith GP, Golden DM, Frenklach M., Goldenberg M. Available at http://www.me.berkeley.edu/gri_mech/

45. Easley WL, Mellor AM, NO decomposition in diesel engines, SAE Paper 1999-01-3546;1999.

46. Tao F. Numerical modeling of soot and $\mathrm{NO}_{\mathrm{x}}$ formation in non-stationary diesel flames with complex chemistry. PhD Thesis. Chalmers University of Technology; 2003.

47. Williams TC, Shaddix CR, Jensen KA, Suo-Anttila JM, Measurement of the dimensionless extinction coefficient of soot within laminar diffusion flames. Int J Heat Mass Transfer 2007;50:1616-30. 


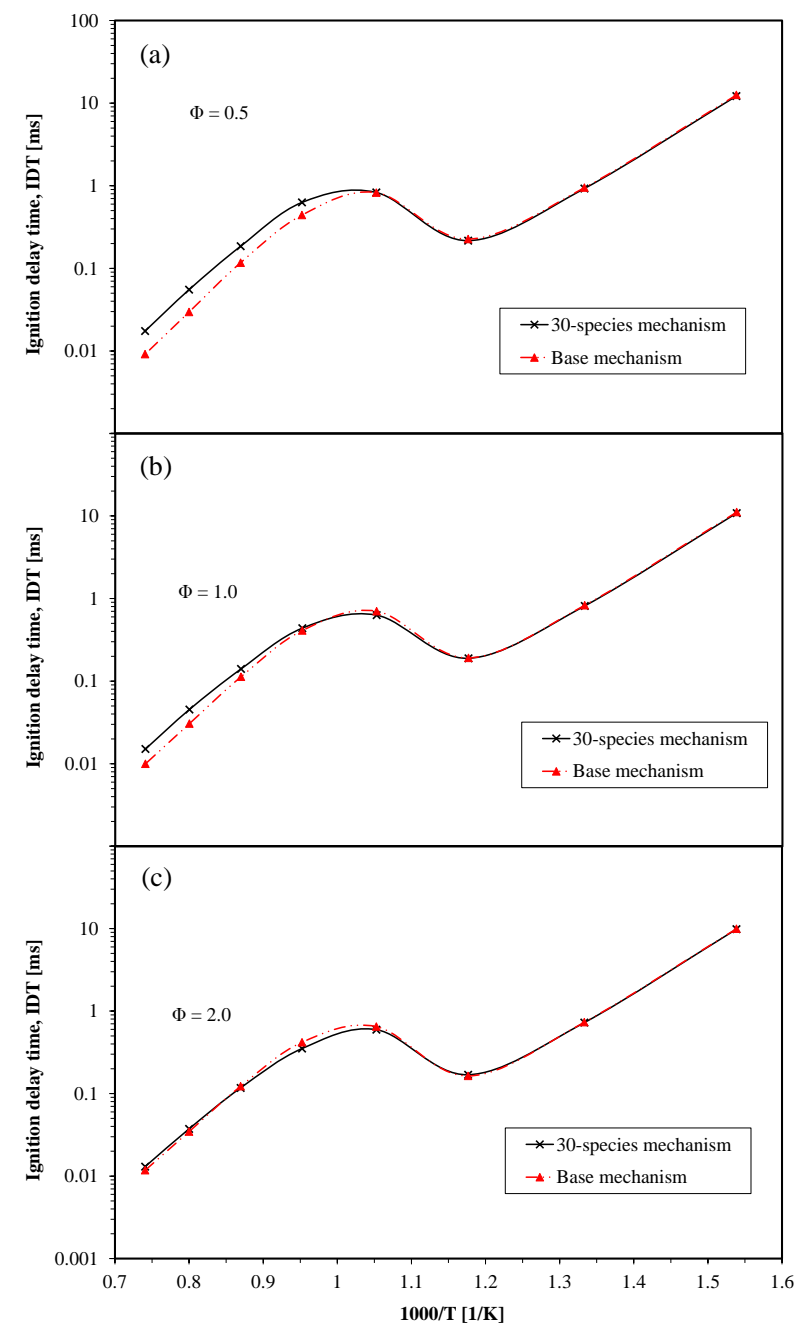

Figure 1. Calculated ignition delay times using the 30 species mechanism and the base counterpart at equivalence ratios of (a) 0.5 , (b) 1.0 and (c) 2.0 . 
(a)

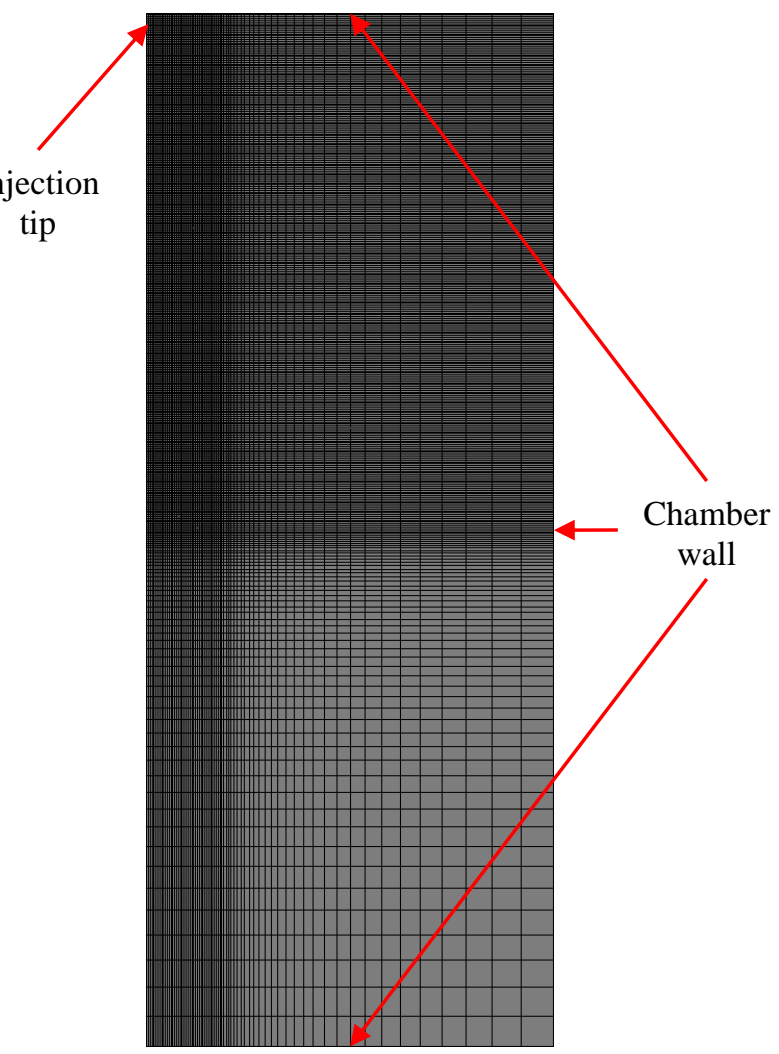

(b)
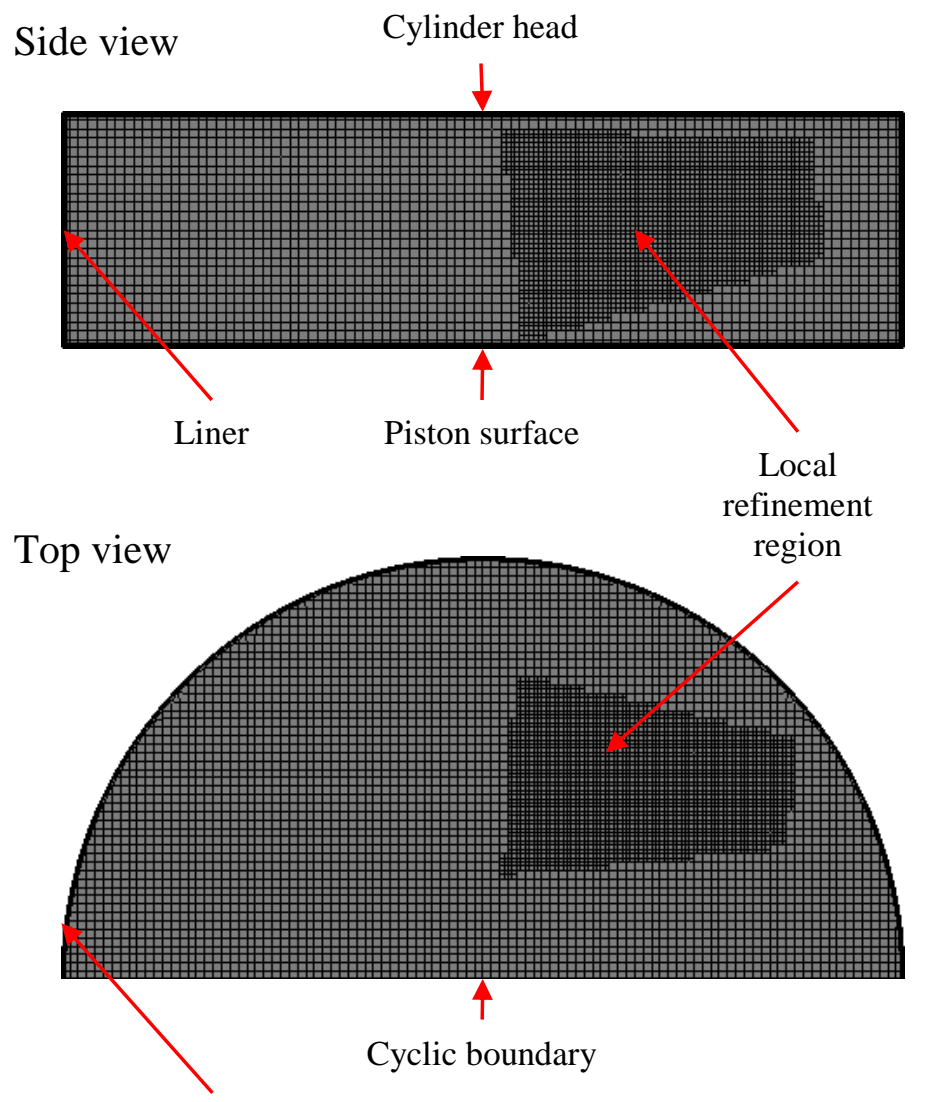

Liner

Figure 2. Cross sections of computational grids for (a) constant volume chamber and (b) marine diesel engine. 

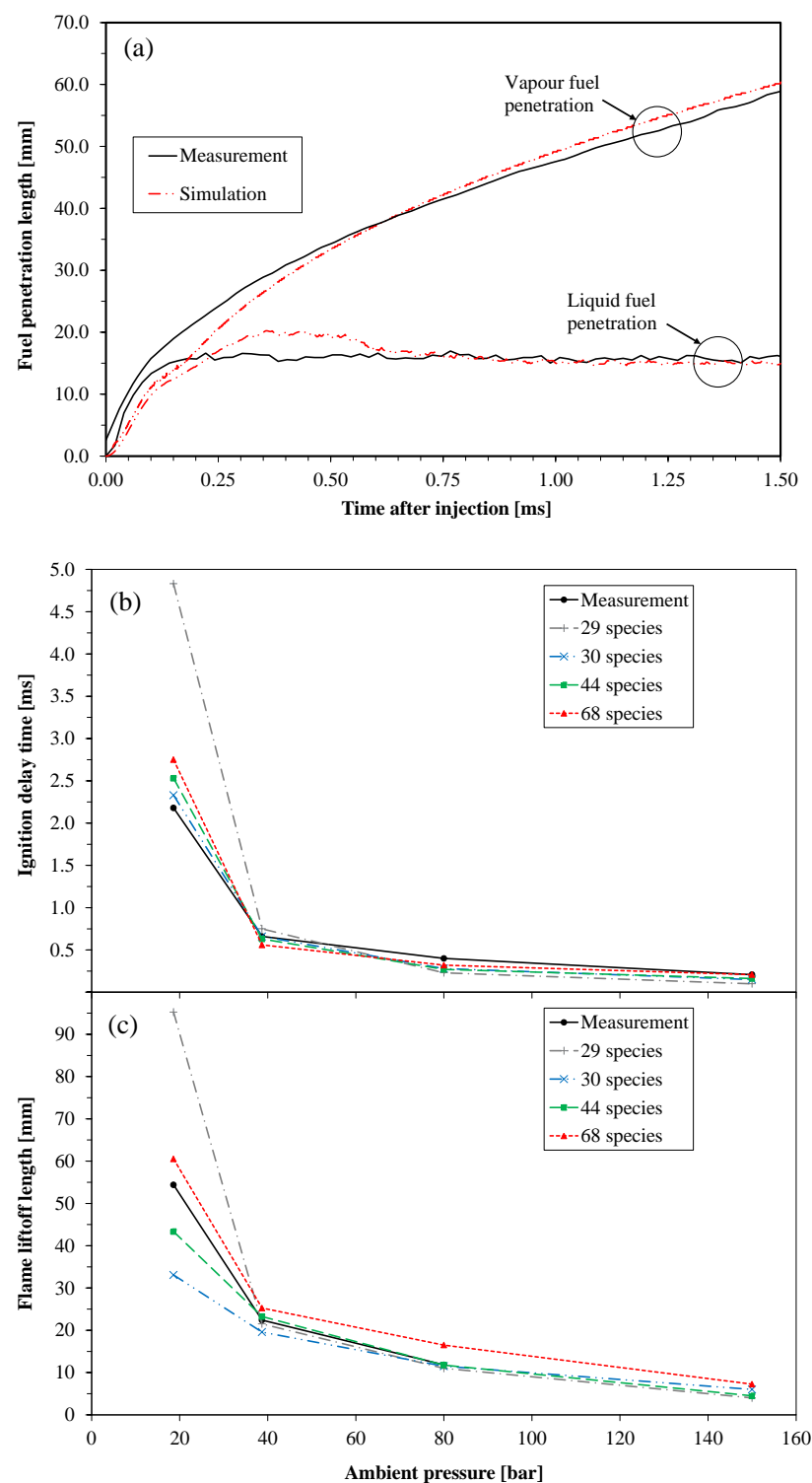

Figure 3. Comparisons of experimental measurement and simulated (a) liquid and vapour fuel penetration lengths as well as (b) ignition delay times and (c) liftoff lengths using various n-heptane mechanisms at different ambient pressure levels. 

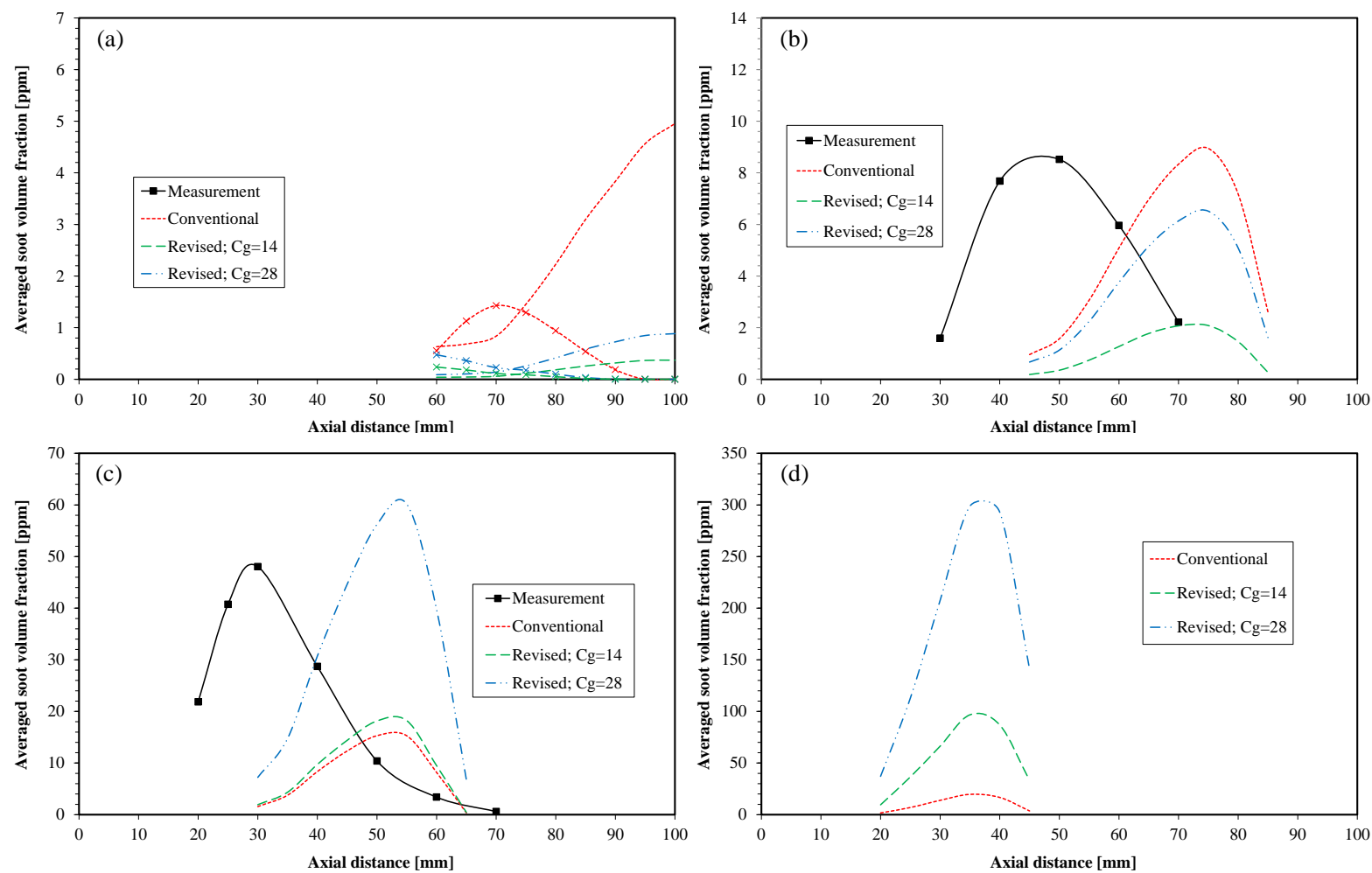

Figure 4. Comparisons of experimental measurement and averaged soot volume fraction using different numerical model configurations at ambient pressure of (a) 18.6, (b) 38.7, (c) 80.0 and (d) 150.0 bar. Lines with markers in Figure 4(a) are results calculated using the 68 species mechanism. 
Figure 5

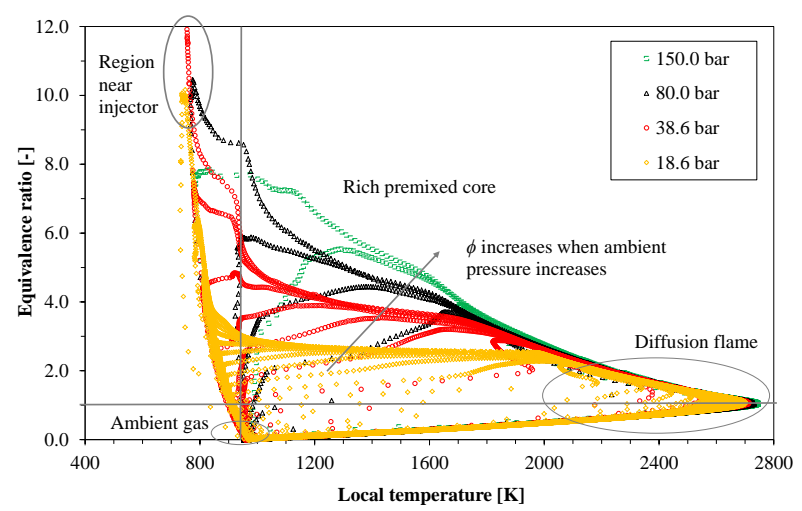

Figure 5. Comparisons of flame structure of diesel spray jets at varying ambient pressure levels in constant volume chamber cases. 
Figure 6

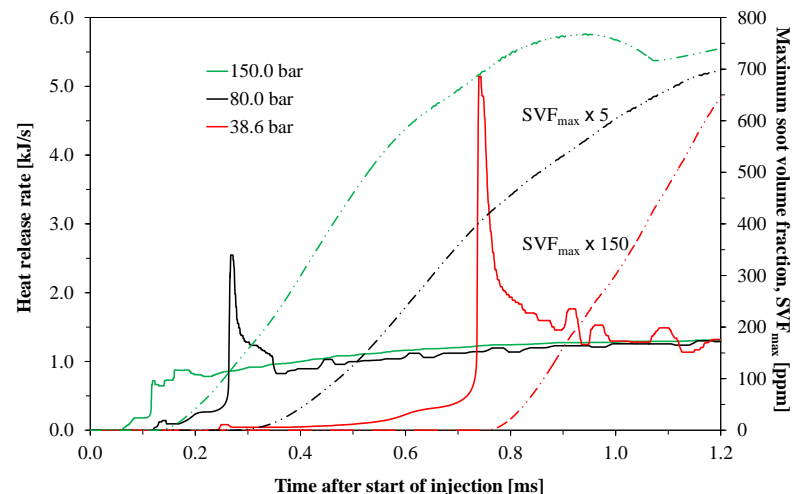

Figure 6. Heat release rate and maximum soot volume fraction in the function of time. 

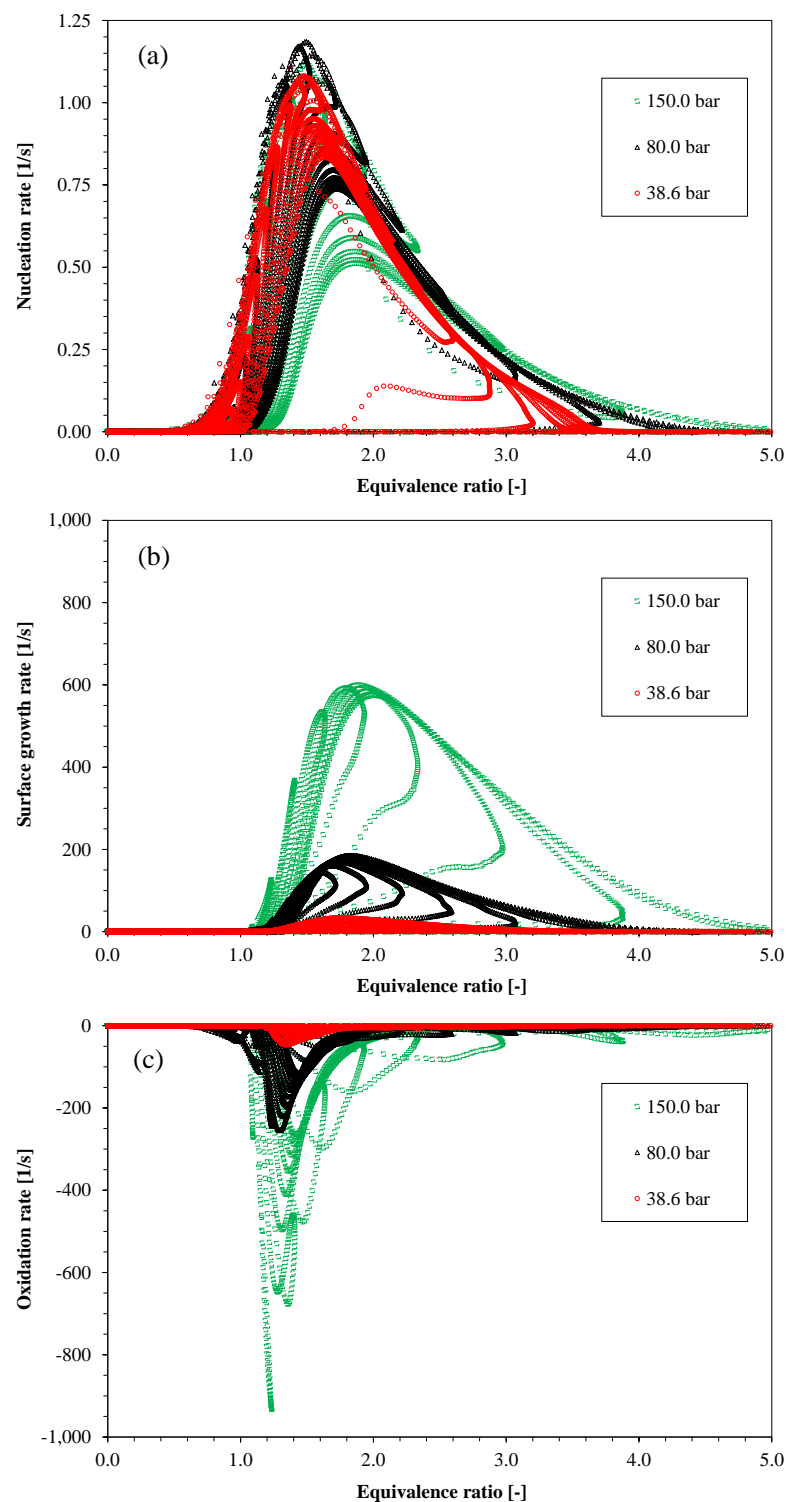

Figure 7.Comparisons of (a) nucleation rate, (b) surface growth rate and (c) oxidation rate at varying ambient pressure levels in constant volume chamber. 


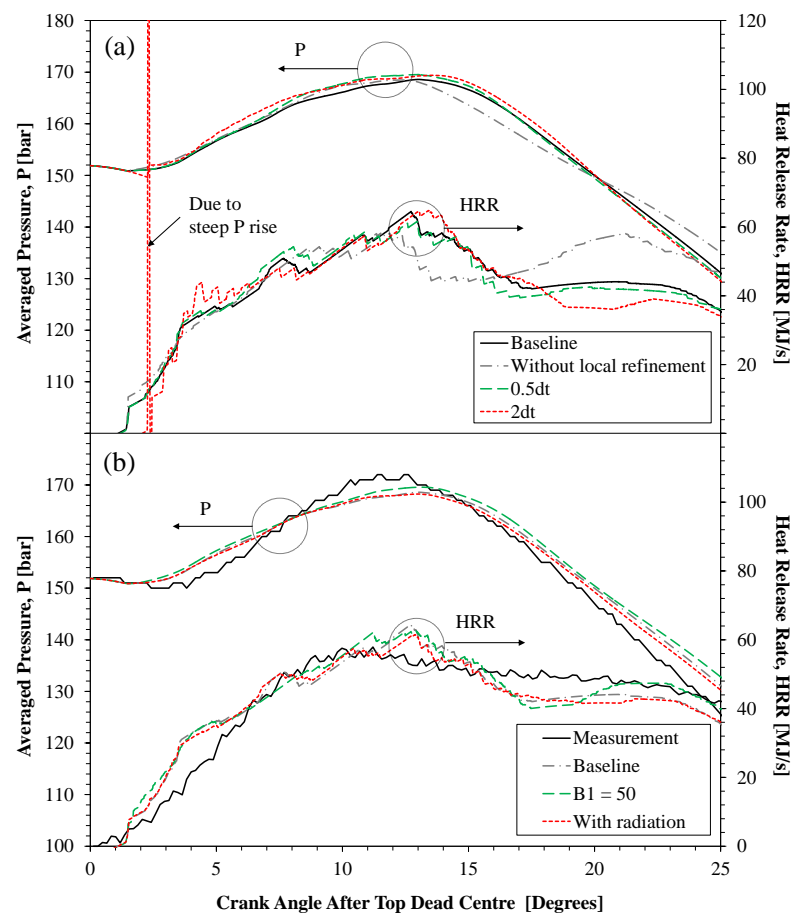

Figure 8. Comparisons of pressure and heat release rate profiles using (a) different spatial and temporal resolutions and (b) different physical models. 

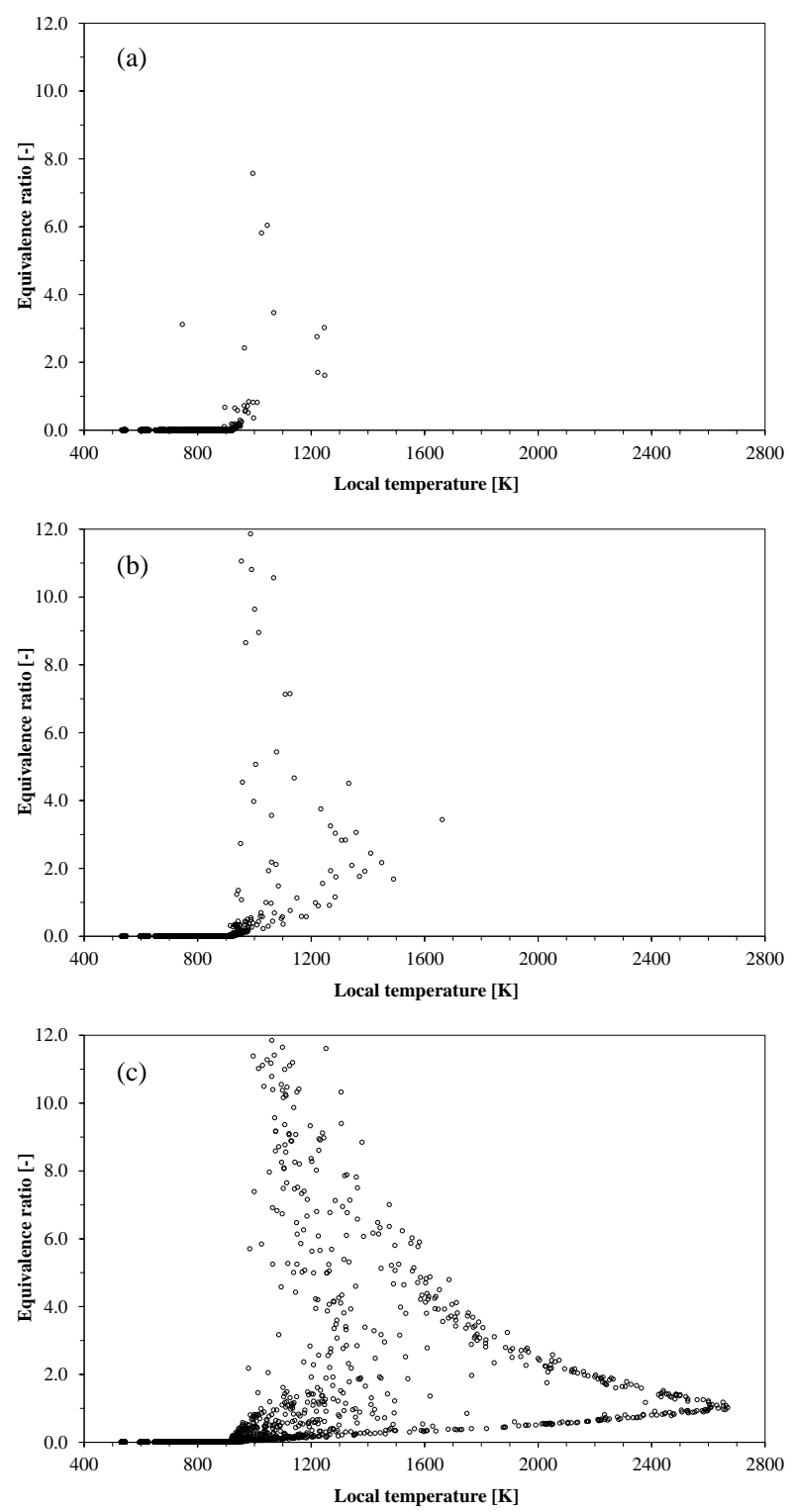

Figure 9. Simulated temperature-equivalence maps as functions of time through auto-ignition at (a) 1.30, (b) 1.35 and (c) 1.50 crank angle degree after top dead centre. 


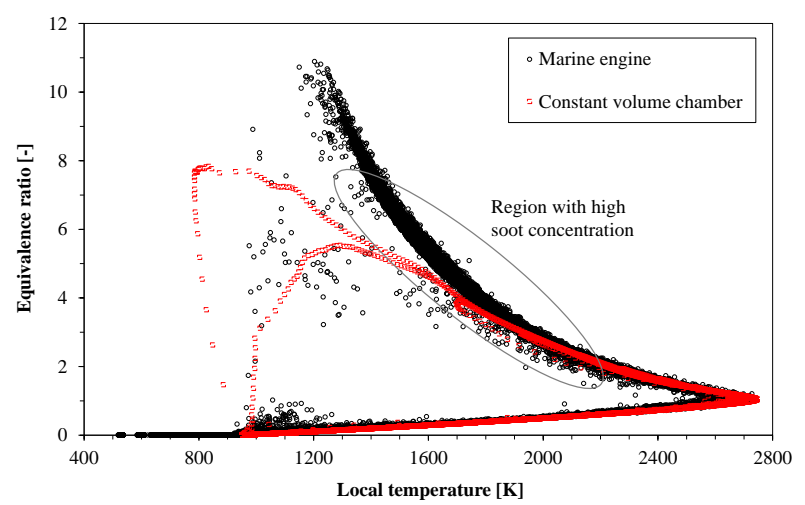

Figure 10. Comparison of flame structure of diesel spray jets in the marine diesel engine and constant volume chamber cases. 

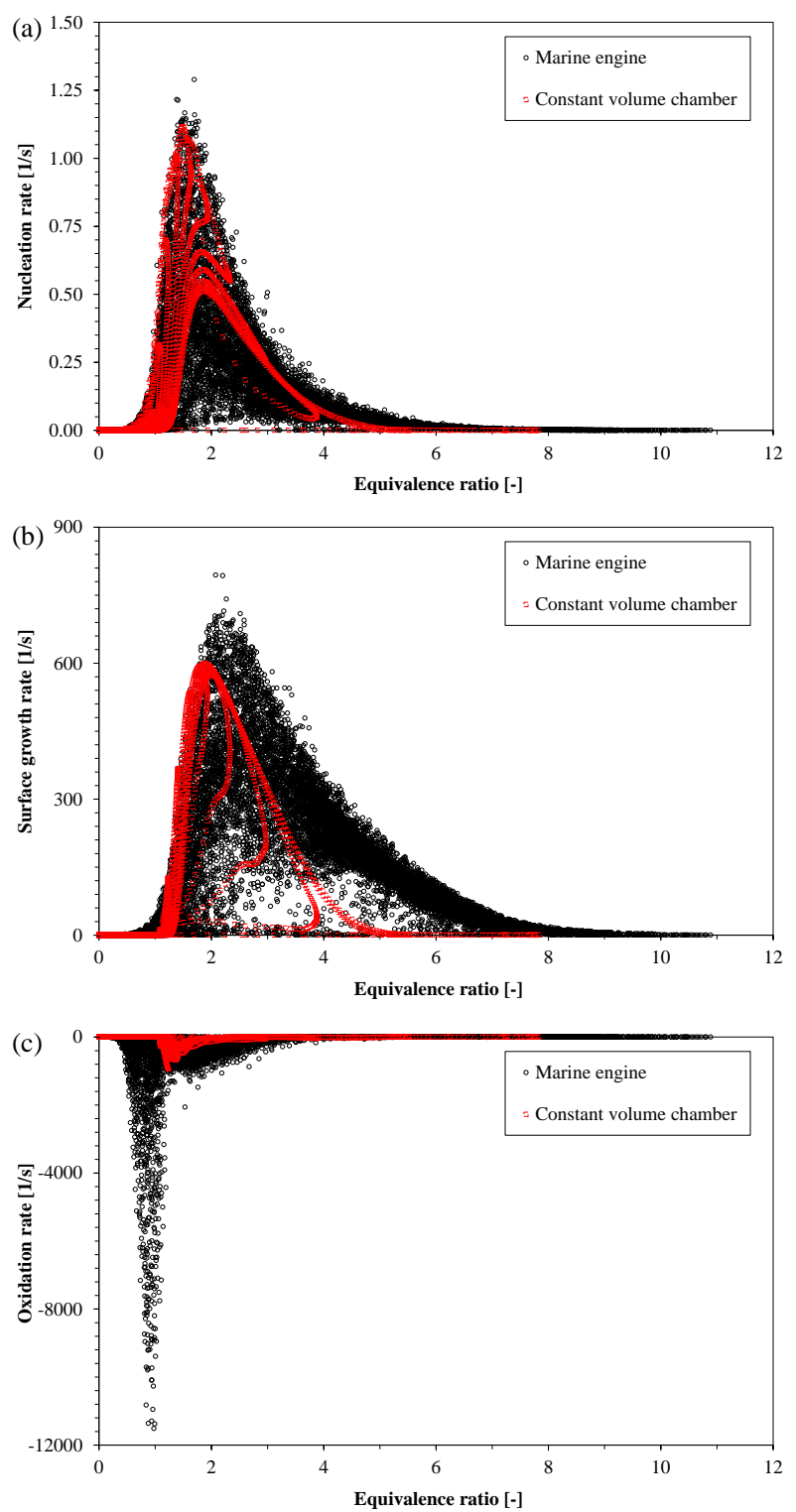

Figure 11. Comparisons of (a) nucleation rate, (b) surface growth rate and (c) oxidation rate in the marine engine and constant volume chamber test cases. 
(a) $\mathrm{CH}_{2} \mathrm{O}$

(b) $\mathrm{OH}$

(c) $\mathrm{C}_{2} \mathrm{H}_{2}$

(d) Soot particles

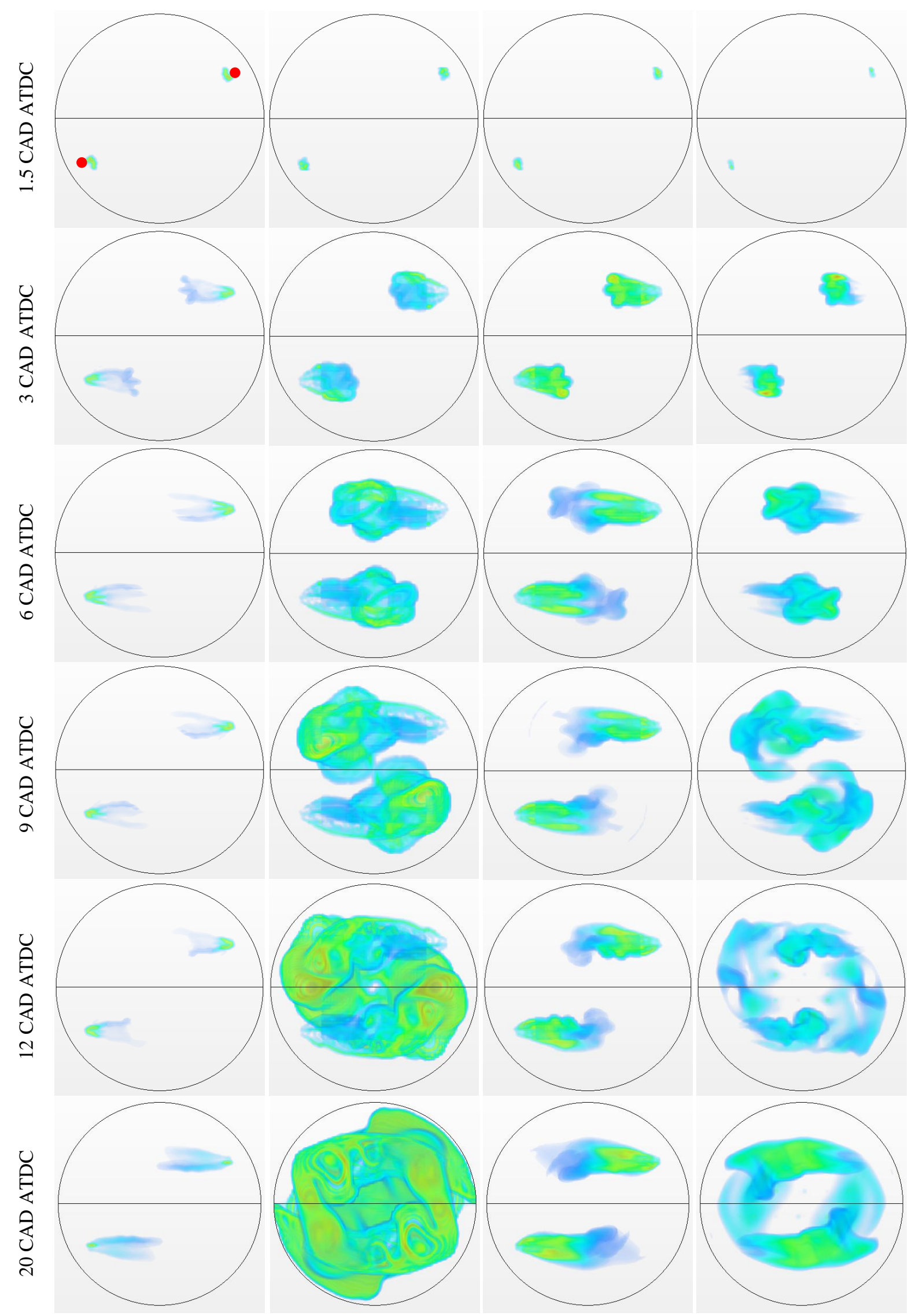

Figure 12. Spatial distributions of (a) $\mathrm{CH}_{2} \mathrm{O}$, (b) $\mathrm{OH}$, (c) $\mathrm{C}_{2} \mathrm{H}_{2}$ and (d) soot particles. The red spots in the top-left figure indicate locations of the injector tips while the centre axis is the cyclic boundary. 


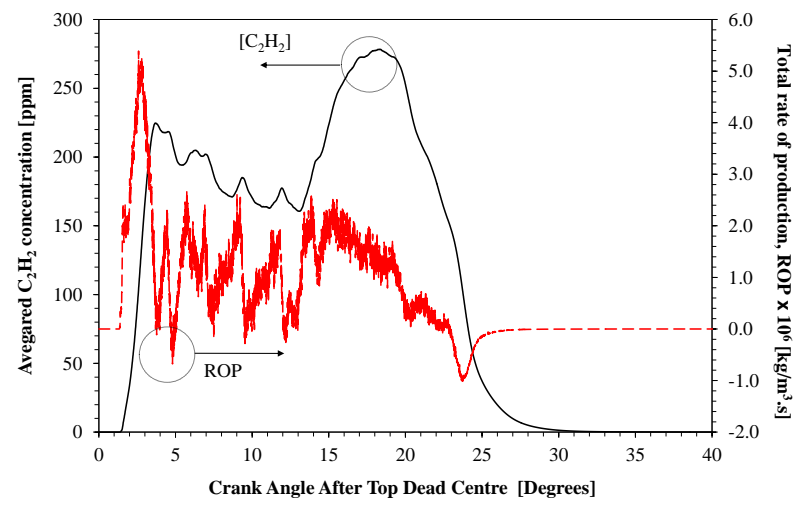

Figure 13. In-cylinder averaged $\mathrm{C}_{2} \mathrm{H}_{2}$ concentration and rate of production. 


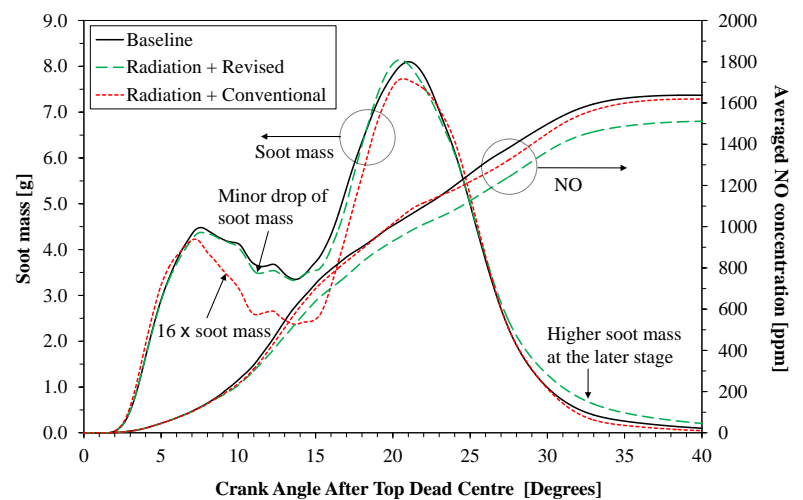

Figure 14. Comparisons of in-cylinder soot mass and averaged NO concentration generated with different physical models. Note: Soot mass calculated using the conventional soot model is scaled up by a factor of sixteen. 


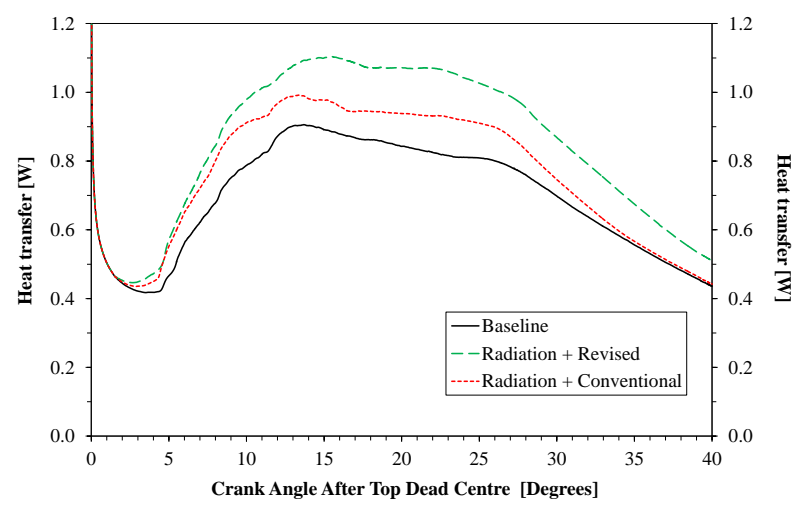

Figure 15. Comparisons of total heat transfer when soot radiation is omitted and calculated using different soot models. 